U.S. DEPARTMENT OF COMMERCE

National Institute of Standards and Technology

\title{
NISTIR 4787
}

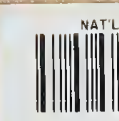

A】l】03 737614

\section{National PDES Testbed}

\section{Report Series}

NIST

PUBLICATIONS

\section{Status Report for First Quarter, FY92}

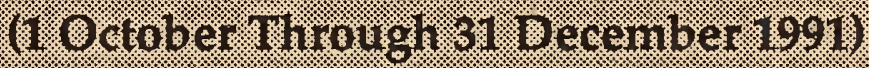

\section{ITlowand MI. Bloom}

NATIONAL

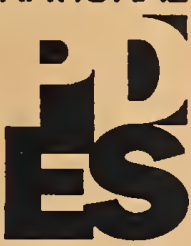

TESTBED TM:

$\angle Q C$

100

.456

4787

1992

C. 2 



\section{National PDES Testbed ReportSeries}

Sponsored by:

U.S. Department of Defense
CALS Evaluation and
Integration Office
The Pentagon
Washington, DC 20301-8000

\section{U.S. Department of Commerce}

Barbara Hackman Franklin,

Secretary

Technology Administration

Robert M. White,

Under Secretary for Technology

National Institute of

Standards and Technology

John W. Lyons, Director

March 1992

\section{Status Report for First Quarter, FY92}

(1 October Through 31 December 1991)

Howard M. Bloom

Chief, Factory Automation Systems Division Manufacturing Engineering Laboratory National Institute of Standards and Technology Gaithersburg, MD 20899 



\section{Foreword}

AS A NEW CENTURY draws near, an emerging information standard will play a key role in making manufactured goods more affordable to develop, buy, and own. Internationally, the standard is known as STEP (STandard for the Exchange of Product Model Data). Domestically, the country's collective efforts supporting STEP's development are referred to as Product Data Exchange using STEP, or PDES.

Once STEP is in place, manufacturers and governments the world over will share a comprehensive rulebook for describing products digitally and passing these descriptions instantly across a broad range of computer hardware and software. The representation will define a product's form and function from conception through consumption.

This standard will be the key by which the defense community will integrate the diverse information systems used in design, manufacturing, and logistics. Such sweeping integration is the goal of an ambitious U.S. Department of Defense (DoD) initiative, Computer-aided Acquisition and Logistic Support (CALS) program.

Since 1988, many of STEP's components and development tools have been tested at the National PDES Testbed (NPT), located in Gaithersburg, Maryland at the National Institute of Standards and Technology. Funded chiefly by the DoD's CALS Evaluation and Integration Office (CEIO), the Testbed staff . . .

- validates specifications or draft standards,

- develops conformance testing methods,

- develops prototypes of STEP applications and application protocols (APs)

- distributes interim STEP Parts and software tools, and

- transfers technology, through Testbed demonstrations, guest researcher programs, and technical reports.

This status report-the first in a series-summarizes the activities and milestones of the Testbed during the first quarter of the U.S. Government's 1992 fiscal year (1Q92). The quarter ran from 1 October through 31 December 1991.

The purpose of this report is to help the CEIO evaluate the Testbed's 1Q92 accomplishments against contract requirements. Toward this end, the report is arranged to correspond with the Office's concerns-and with the Testbed's FY92 Statement of Work. The final section describes how Testbed personnel have helped spread the word about STEP to the defense industry, industry at large, the general public, and the Administration. For brevity and flow, supporting tables have been placed in an appendix. 
National PDES Testbed-1Q92 Status Report 


\section{Executive Summary}

$\mathbf{T}$

HE ANNUAL MEETINGS of two standards bodies, followed by CALS Expo '91, made 1Q92 a busy quarter for STEP working groups, advisory groups, and technical committees. Their agendas, in turn, drove much of the activity of the National PDES Testbed, whose technical staff now hold 18 lead or contributory posts in these organizations. Meanwhile, at quarter's end the Testbed's new budget remained unresolved. As a result, portions of two support efforts (Configuration Management and Conformance Testing) were indefinitely deferred. However, in the increasingly critical domain of external coordination, the quarter proved to be the busiest in three years. Through meetings, tutorials, demonstrations, and technical reports, Testbed personnel lent strong support to industry and the entire STEP community.

Management and Administrative Support-A new Testbed project manager, S. Jeane Ford, was selected to replace Chuck McLean, who had left at the end of FY91 to pursue independent research. Also, a technical writer/editor joined the Project Management Office to make technology transfer more rapid and effective.

Travel Coordination and Operational Support-The Testbed sponsored 29 trips in support of its mission. CALS Expo '91 and the joint IPO/ISO meeting made the quarter's travel schedule unusually busy. In other trips, staff represented the Testbed at seminars and working groups. At NIST the Testbed Computer Support staff installed and integrated hardware and software, trouble-shooted, and upgraded the Validation Testing Laboratory.

DoD Requirements for STEP-The Project Plan was developed for the AP (Application Protocol) Framework and Methodology-the effort that defines, plans, and manages PDES/STEP AP projects to most efficiently use development resources. The Plan was approved by the Project Management Advisory Group (PMAG) of ISO Technical Committee (TC) 184 (Industrial Automation Systems), Subcommittee (SC) 4 (Industrial Data and Global Manufacturing Programming Languages). The PMAG appointed the Testbed's AP Framework project manager to be the AP Coordinator for STEP. Under the Application Protocol for Inspection Planning project, STEP's Shape Tolerance Model was compared against 11 related standards, and the findings documented for publication. Working ties were forged with members of ISO and IPO, and a work-sharing agreement was informally established with German counterparts in the European R\&D program, ESPRIT.

Technical Support for Standards Organizations-Testbed personnel continued to head working groups and committees of ISO (International Organization for Standardization) and IPO (IGES/PDES Organization). Three new chairs were accepted, and a Testbed project manager was elected "Owner" of STEP Part 47 (Shape Tolerance). Under the Configuration Management project, more than 900 files were requested nationwide from 
the STEP On-Line Information Service. The Configuration Management Comprehensive Requirements Document began undergoing formal review. In NIST-funded support efforts, NIST specialists helped the electronics industry merge the data models of four ANSI standards into a single model that would define electronics data for STEP. And, as the National Initiative for Product Data Exchange neared its January kickoff, NIST personnel from the IGES/PDES/STEP Office, the ISO TC184/SC4 Secretariat, and the Testbed planned their coordinated support.

Technical Coordination with Industry-Testbed staff supported eight technical thrusts of the PDES, Inc. consortium, including the STEP Data Access Interface (SDAI) Specification. Testbed directories were redesigned so that old and new versions of the Express parser could be operating at the same time. (Previously, remote users requiring one version had to wait until users of the other version were finished.) Together with two industry representatives, the PDES, Inc. liaison developed a STEP/PDES tutorial and conducted it for more than 90 attendees at CALS Expo. He also trained Testbed users and coordinated a team meeting for the STEP Data Access Interface (SDAI). The SDAI prototype implementation of a major computer vendor was demonstrated. In a NISTfunded effort, a NIST engineer met with the PDES, Inc. Electrical/Electronics Team. The team approved his plan to develop software tools that will help industry incorporate the ANSI "harmonized" data model into STEP.

Testing-Data Probe, the Testbed's improved software tool for editing STEP data, received a first public look. A major upgrade of the Fed-X compiler, together with new documentation, was being readied for dstribution.

Education and Technology Transfer-Five technical reports were issued, chiefly on validation testing. A multimedia tutorial on the changing face of product data was completed. The tutorial, which is based on interactive software, was a hit at CALS Expo '91. Expo attendees were eager to learn more about PDES after hearing the kickoff speech for the National Initiative for Product Data Exchange, delivered by Dr. Robert M. White, Undersecretary for Technology, Department of Commerce. At Expo, Testbed personnel led three tutorials, chaired one track, and delivered presentations on STEP technical issues. While visiting NIST, a White House staff member toured the Validation Testing Laboratory. So did some 350 visitors from Government, industry, and academia, during NIST's annual Automation Open House. 


\section{Acknowledgments}

This quarterly report was compiled from internal monthly status reports and other documents written by the project managers of the National PDES Testbed:

Manager

J. Newton Breese Shaw C. Feng James E. Fowler Cita M. Furlani Clarence Johnson Susan Katz

Scott Paisley Mark E. Palmer Sanford P. Ressler Charles W. Stark

\section{Project}

Testbed Readiness

AP for Inspection Planning

STEP Implementation Tools

Conformance Testing Services; IPO/ISO Support

Project Coordination Office

Configuration Management Systems and Support

Testbed Computer Support

AP Framework and Methodology

Validation Testing Systems

PDES, Inc. Liaison; PDES, Inc. Technical Program Support

Eight others at NIST contributed materially to this report:

William Conroy Manager, National Initiative for Product Data Exchange

Merrill M. Hessel

Michael McLay

Mary Mitchell

Julie Parker

Curtis Parks

David A. Sauder

Paul F. Stregevsky
Deputy Manager, National Initiative for Product Data Exchange Electricity Division

Product Data Engineering Group, Factory Automation Systems Division

Integrated Systems Group, Factory Automation Systems Division Electricity Division

Product Data Engineering Group, Factory Automation Systems Division 
National PDES Testbed-1Q92 Status Report 
W ITH THIS QUARTERLY REPORT, The National PDES Testbed (NPT) and its host, the National Institute of Standards and Technology (NIST), begin an important new report series. The Testbed, as its name suggests, has been the nation's focal point for testing and validating the specifications for STEP (STandard for the Exchange of Product model data). These important missions continue. But as the pace accelerates to develop and implement JCALS (Joint Computer-aided Acquisition and Logistic Support), so must PDES (Product Data Exchange using STEP), the national effort to develop the product data model that will give JCALS much of its functionality.

While it is years too soon to hail the Year of STEP, it can safely be said that FY92 begins a critical phase for PDES, and in turn for the National PDES Testbed. As the second quarter got underway, the Department of Commerce launched the National Initiative for Product Data Exchange. The Initiative will accelerate product data exchange (PDE) research. A key goal is to ensure that the companies, Government agencies and programs, standards organizations, R\&D consortia, and other parties supporting PDES coordinate their efforts more closely.

With diffuse efforts aligned under a single banner, the United States will have a strong voice in determining STEP's content and form. It falls to the National PDES Testbed to ensure that this voice is in harmony with itself . . . and in step with the product-data concerns of both our nation and its allies.
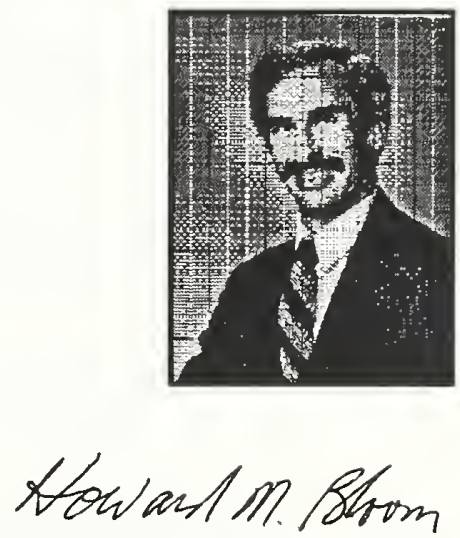

Howard M. Bloom, Chief Factory Automation Systems Division Acting Manager, National PDES Testbed 
National PDES Testbed-1Q92 Status Report 


\section{Oontents}

Section

Page

Foreword . V

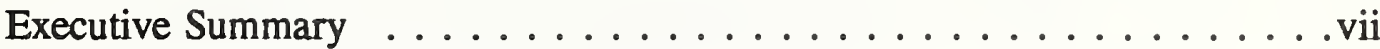

Acknowledgments $\ldots \ldots \ldots \ldots \ldots \ldots \ldots \ldots \ldots$

Manager's Message ............................ . . . .

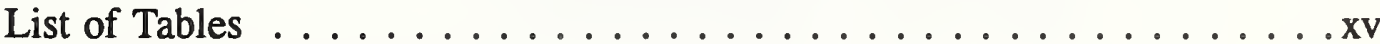

List of Figures $\ldots \ldots \ldots \ldots \ldots \ldots \ldots \ldots$

$1.0 \quad$ INTRODUCTION $\ldots \ldots \ldots \ldots \ldots \ldots \ldots \ldots \ldots \ldots \ldots \ldots$. $1-1$

2.0 MANAGEMENT AND ADMINISTRATIVE SUPPORT . . . . . . 2-1

3.0 TRAVEL COORDINATION AND OPERATIONAL SUPPORT _... 3-1

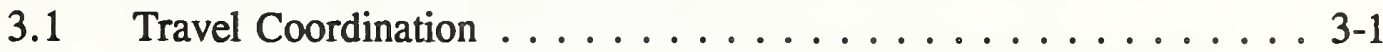

3.2 Testbed Computer Support (TCS) ............... 3-1

4.0 DoD REQUIREMENTS FOR STEP ..................4

4.1 AP Framework and Methodology ... . . . . . . . . . . . . 4-1

4.2 Application Protocol for Inspection Planning (NIST-Funded) . . . 4-3

4.3 Three Projects Placed on Hold. . . . . . . . . . . . . . . . . 4-4

5.0 TECHNICAL SUPPORT FOR STANDARDS ORGANIZATIONS . . 5-1

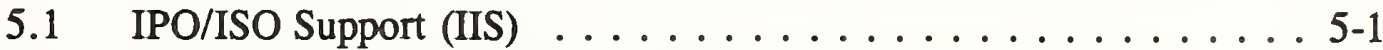

5.2 Configuration Management Systems and Services (CMS\&S) . . . 5-3

5.3 Noncontractual Support . . . . . . . . . . . . . . . . 5-4

5.3.1 Electrical "Harmonization" Project (NIST-Funded) . . . . 5-5

5.3.2 National Initiative for Product Data Exchange (NIST-, DoD-, and Industry-Funded) .................. 5-5 
$\underline{\text { Section }}$

$\underline{\text { Page }}$

6.0 TECHINICAL COORDINATION WITH INDUSTRY . . . . . . 6-1

6.1 PDES, Inc. Technical Program Support . . . . . . . . . . . 6-1

6.2 Testbed Readiness and Support . . . . . . . . . . . 6-2

6.3 PDES, Inc. Liaison . . . . . . . . . . . . . . . . . . 6-2

6.4 STEP Data Access Interface Demonstrated by DEC . . . . . . 6-3

6.5 PDES, Inc. Electrical/Electronics Team (NIST-Funded) . . . . . 6-4

7.0 TESTING $\ldots \ldots \ldots \ldots \ldots \ldots \ldots \ldots \ldots \ldots \ldots \ldots \ldots . \ldots \ldots$

7.1 Validation Testing Systems (VTS) $\ldots \ldots \ldots \ldots \ldots \ldots$. . . . . .

7.2 Conformance Testing Services (CTS) $\ldots \ldots \ldots \ldots \ldots \ldots$. . . . . .

7.3 STEP Implementation Tools (SIT) $\ldots \ldots \ldots \ldots \ldots$. . . . . . 7-3

8.0 EDUCATION AND TECHNOLOGY TRANSFER ......... 8-1

8.1 Product Data Education Goes Multimedia . . . . . . . . . 8 8-1

8.2 Interest in PDES Sparked at CALS Expo '91 . . . . . . . . 8-2

8.3 Testbed Personnel Conduct Expo Sessions on PDES, APs . . . . . 8-2

8.4 White House Assistant Visits Testbed . . . . . . . . . . 8-3

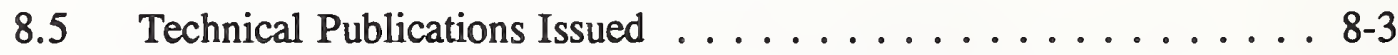

8.6 STEP, Testbed on Display at Automation Open House . . . . . . 8 8-3

Appendix: Reference Data $\ldots \ldots \ldots \ldots \ldots \ldots \ldots$. . . . . . . 


\section{List of Tables}

Table

$\underline{\text { Page }}$

3-1. 1Q92 Trips Funded by the National PDES Testbed. . . . . . . . . . . . . 3-2

4-1. Sample Table Comparing Tolerancing

Practices Across Several Standards. . . . . . . . . . . . . . . . 4-3

8-1. Technical Reports Published by the National PDES Testbed, 1Q92. . . . 8 8-4

A-1. Dimensioning Standards Compared in Task 1

of AP for Inspection Planning. . . . . . . . . . . . . A-1

A-2. Testbed Staff Members' ISO Roles that are

Candidates for Funding from the IPO/ISO Support Project. . . . . . . . A A-2

A-3. Testbed Staff Members' IPO Roles that are

Candidates for Funding from the IPO/ISO Support Project. . . . . . . . A A-3

A-4. Main Directories in the STEP On-Line

Information Service (SOLIS) as of 31 December 1991 . . . . . . . . A-4

National PDES Testbed Events

Scheduled for February Through June 1992. . . . . . . . outer back cover 


\section{List of Figures}

Figure

Page

1-1. DoD's Critical Technologies Plan calls for

STEP-based mechanical-parts product-data systems by $1996 . \ldots \ldots$. . . 1-2

1-2. STEP is a critical open standard that will enable the DoD to implement CALS. . . . . . . . . . . . . . . 1-4

1-3. Foundation of STEP. . . . . . . . . . . . . . 1-5

4-1. Major Milestones for AP Framework and Methodology. . . . . . . . . . 4-2

5-1. Major Milestones for IPO/ISO Support. . . . . . . . . . . . . 5-3

5-2. Major Milestones for Configuration Management Systems and Services. . . 5-4

6-1. Major Milestones for PDES, Inc. Technical Program Support. . . . . . . 6-2

6-2. Major Milestones for Testbed Readiness and Support. . . . . . . . . . 6-3

6-3. STEP-compliant wireframe images and data were transferred across applications in a demonstration of DEC's STEP Data Access Interface (SDAI). . . . . . . . . . 6-4

7-1. In this Data Probe screen, a user creates a STEP information unit, "Transformation" (bottom center) by picking an Entity Type (right). She will pass it to a STEP exchange file (top center, menu). . . . . . . 7-1

7-2. Major Milestones for Validation Testing Systems. . . . . . . . . . . . 7-3

7-3. Major Milestones for STEP Implementation Tools. . . . . . . . . . . . 7-4

8-1. The importance of product-data standards to competitiveness is brought home in this interactive multimedia tutorial. . . . . . . . 8-1

8-2. Visitors received a first-hand look at STEP development tools during NIST's annual Automation Open House. Shown is the Express-to-SQL translator, developed by the National PDES Testbed. . . 8 8-4 
8-3. At NIST's Automation Open House, this wireframe image was rendered by the C4 Visualizer, a STEP software tool donated by PDES, Inc. member General Motors. . . . . . . . . . . 8-5

8-4. Hundreds learned about the National PDES Testbed in posters like this one at NIST's 1991 Automation Open House. . . . . . 8 8-5 
No approval or endorsement of any commercial product by the National Institute of Standards and Technology is intended or implied. The work described was funded by the United States Government and is not subject to copyright. 


\subsection{Introduction}

ACROSS THE WORLD, thousands of individuals are working to develop an ambitious international standard to describe manufactured goods in digital form. Internationally, the standard is known as STEP (STandard for the Exchange of Product Model Data). Domestically, efforts toward STEP are collectively known as PDES (Product Data Exchange using STEP).

Within PDES, much of STEP's development, testing, validation, and technical coordination comes together at the National PDES Testbed (NPT), located at the National Institute of Standards and Technology (NIST) in Gaithersburg, Maryland. When the Testbed was created in 1988, its focus was fixed squarely on PDES, which then stood for Product Data Exchange Specification. There were two objectives:

- create software tools to help develop STEP-compliant software.

- Provide a framework in which the resulting software products could be tested and validated.

These original objectives remain. But as the Department of Defense (DoD) has moved forward in CALS (Computer-aided Acquisition and Logistic Support), a second focus has emerged. In that focus, the Testbed recognizes that the STEP product-data standard will be the backbone supporting many CALS functions. As such, it must be sufficiently robust to meet the multifaceted needs of the U.S. armed forces and their contractors.

Viewed in this light, PDES-and the National PDES Testbed-are linchpins for CALS. Yet, the same might be said of scores of other CALS projects. Recognizing the need to set priorities, in 1991 the DoD established the CALS Evaluation and Integration Office (CEIO). In so doing, the DoD underscored that each CALS project, no matter how important, is but one piece of a large picture . . . and that no piece operates in a technical or budgetary vacuum.

Meanwhile, in the standards community, it was becoming increasingly clear that product data exchange would play a key role in enterprise integration. Hence, NIST was refocusing the Testbed's strategy in a way that would support three CALS strategic objectives:

- Reduce lead time, by using a shared data environment and support modeled after the Navy's successful system, RAMP (Rapid Acquisition of Manufactured Parts).

- Reduce cost, by eliminating duplicate data and providing accurate digital technical information. 
- Improve quality, by ensuring data consistency to support the application of powerful tools of computer-aided design (CAD) and computer-aided engineering (CAE).

STEP will play a critical role in meeting these objectives. STEP also will be a key standard for meeting the Flexible Manufacturing milestones set forth in the DoD's Critical Technologies Plan (1 May 1991). According to those milestones, by 1996 the DoD is to have in place a STEP-based provisioning system that will rapidly make-toorder machined mechanical parts, as diagrammed in Figure 1-1.

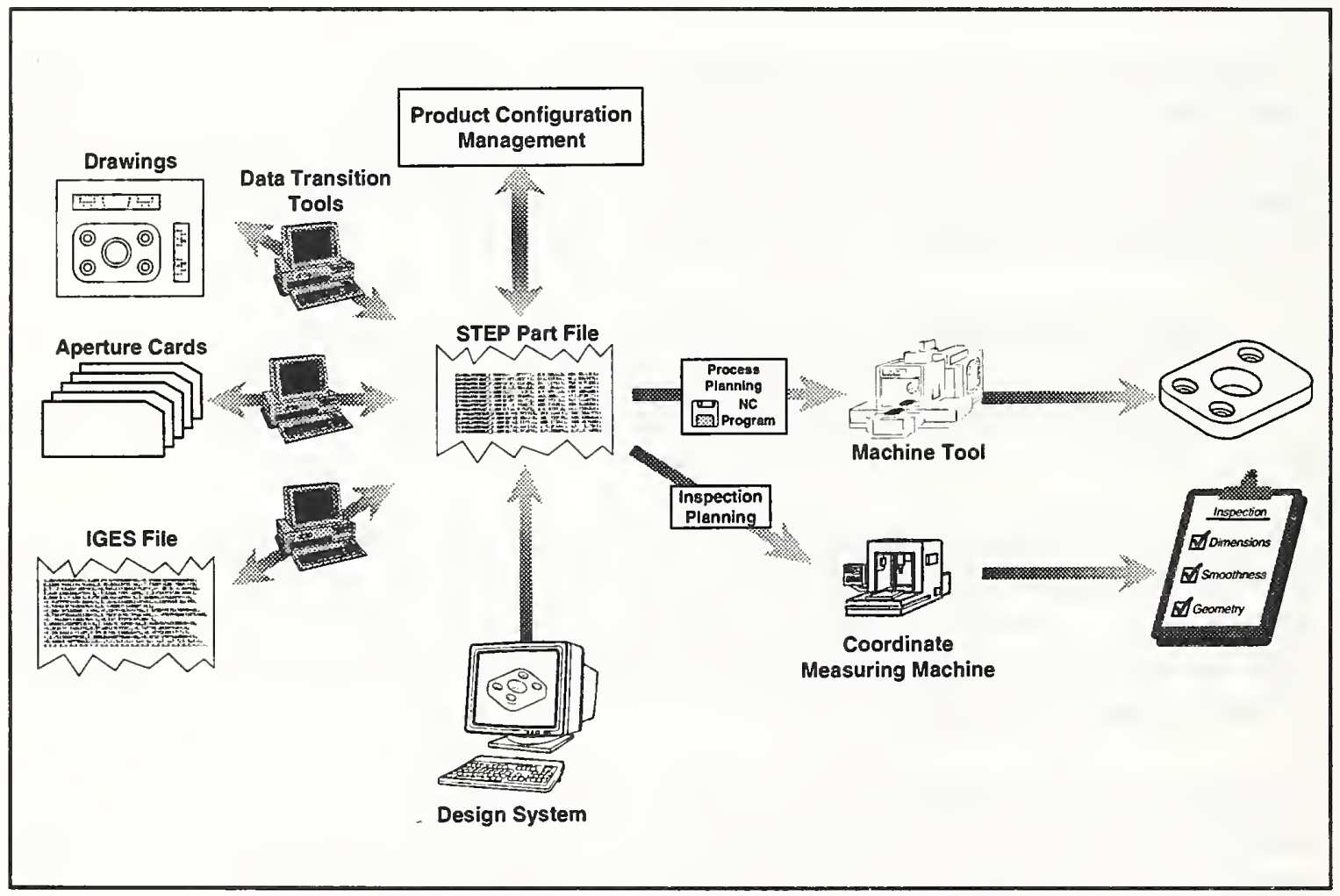

Figure 1-1. DoD's Critical Technologies Plan calls for STEP-based mechanical-parts product data systems by 1996.

But before this scenario can take shape, certain pieces of CALS must fall in place. That was the conclusion of the CALS Architecture Study (June 1991), which cited two technological voids:

- Testing methodologies are inadequate.

- Standards critical to CALS (particularly, STEP) are not yet fully developed. ... and made four recommendations:

- Develop a full set of product-data user requirements. 
- Develop standards as a harmonized package, interfacing with existing and emerging information-technology standards, as appropriate.

- Provide conformance testing to validate vendor claims.

- Develop data models, for these are critical to standardization.

Anticipating these concerns, the National PDES Testbed has been working closely with the critical organizations participating in PDES/STEP. The coordination has four thrusts:

1. Work with DoD agencies to ensure that requirements are developed to meet national defense needs.

2. Work with national and international standards organizations to ensure that STEP standards are adopted in a timely and useful manner and meet DoD requirements.

3. Work with industry (primarily through the PDES, Inc. consortium) to ensure that STEP is accepted and implemented.

4. Take the lead in developing the testing methodologies and services.

Originally, the Testbed's projects fell into three domains. But in 1991, to respond to the move toward improved coordination, the original three were broken out into six:

1. Management and Administrative Support

2. Travel Coordination and Operational Support

3. DoD Requirements for STEP

4. Technical Support for Standards Organizations

5. Technical Coordination with Industry

6. Testing

The first two domains provide support for the remaining four. These, in turn, reflect the increased coordination between the Testbed and critical organizations.

Each domain comprises projects with goals of their own. But the project goals come together in six Testbed goals:

- Develop a set of quality application protocols (APs) to meet the roadmap of the Critical Technologies Plan.

- Put in place procedures for testing whether vendor software conforms with STEP.

- Gain international approval for domestically developed STEP standards, making it unnecessary for the DoD to issue MIL-SPECs.

- Merge STEP Application Protocols into the DoD-CIM (Corporate Information Management) data model, IWSDB (Integrated Weapon System Data Base). 
- Provide for legacy data-data that predates the STEP standard.

- Build a network of DoD facilities developing experience with STEP.

As these goals fall into place, they will lead to the establishment of a DoD facility environment where mechanical parts can be designed, machined, and inspected using STEP (Figure 1-2). This, too, will be but a piece of the CALS picture. But piece by piece, the picture will come together. The Testbed is proud to play a role.

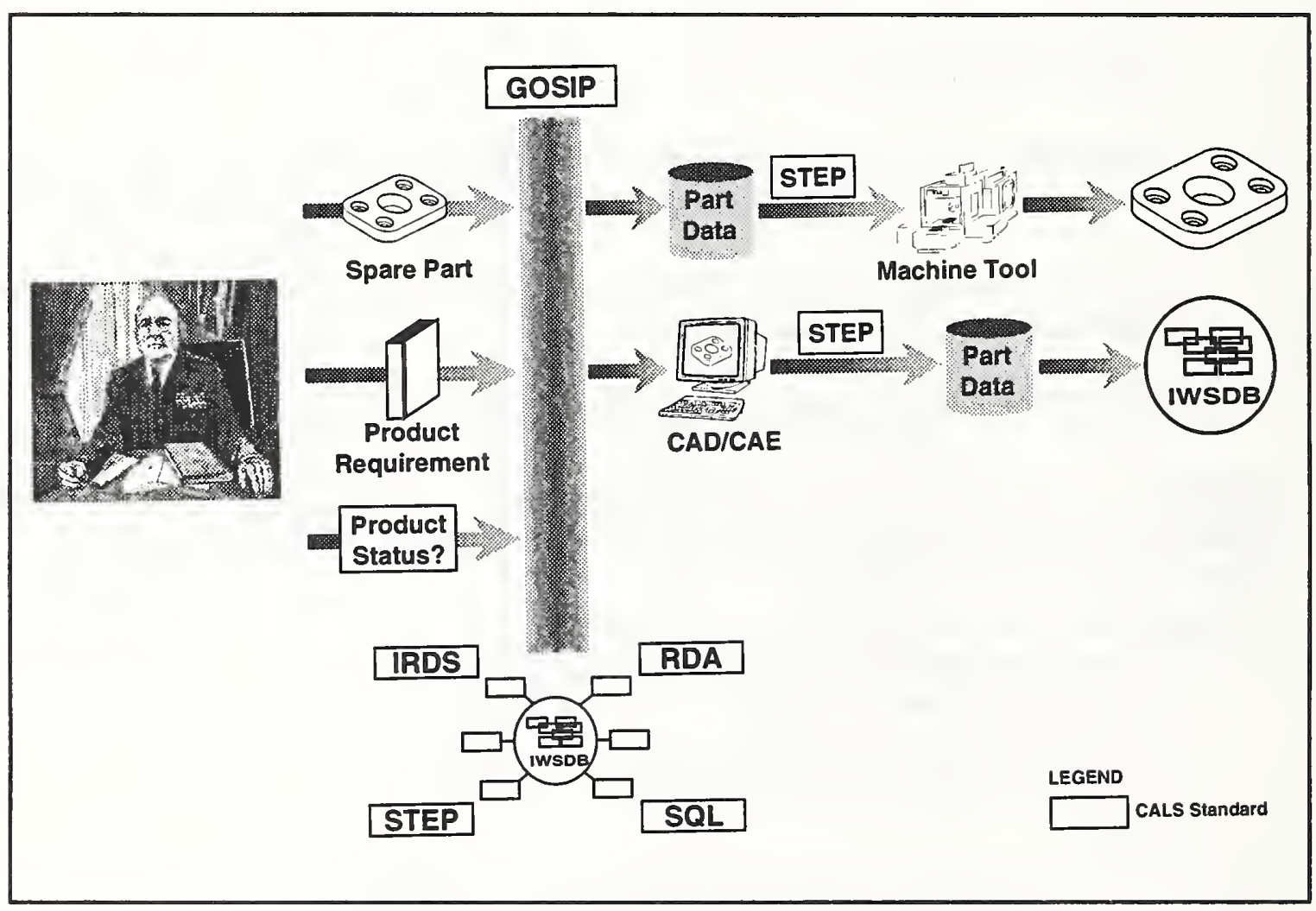

Figure 1-2. STEP is a critical open standard that will enable the DoD to implement CALS.

\section{Brief Overview of the STEP Technology and Standards}

Consider Figure 1-3. Basically, the end-user community-for example, an aerospace prime manufacturer, a repair \& maintenance ( $\&$ \& $)$ center, or a DoD spares depot-has requirements for implementing systems that use the STEP methodology. These requirements are converted to Application Protocols, referred to as $A P s$, that define an application scope (such as process planning for machined mechanical parts), the information to be exchanged between the application and a data repository (such as'a file or shared database), and conformance specifications to help the STEP developers implement the AP correctly.

The APs become subsets of STEP that systematically increase its capability. They are built upon Resource Models that define a generic set of basic product information 


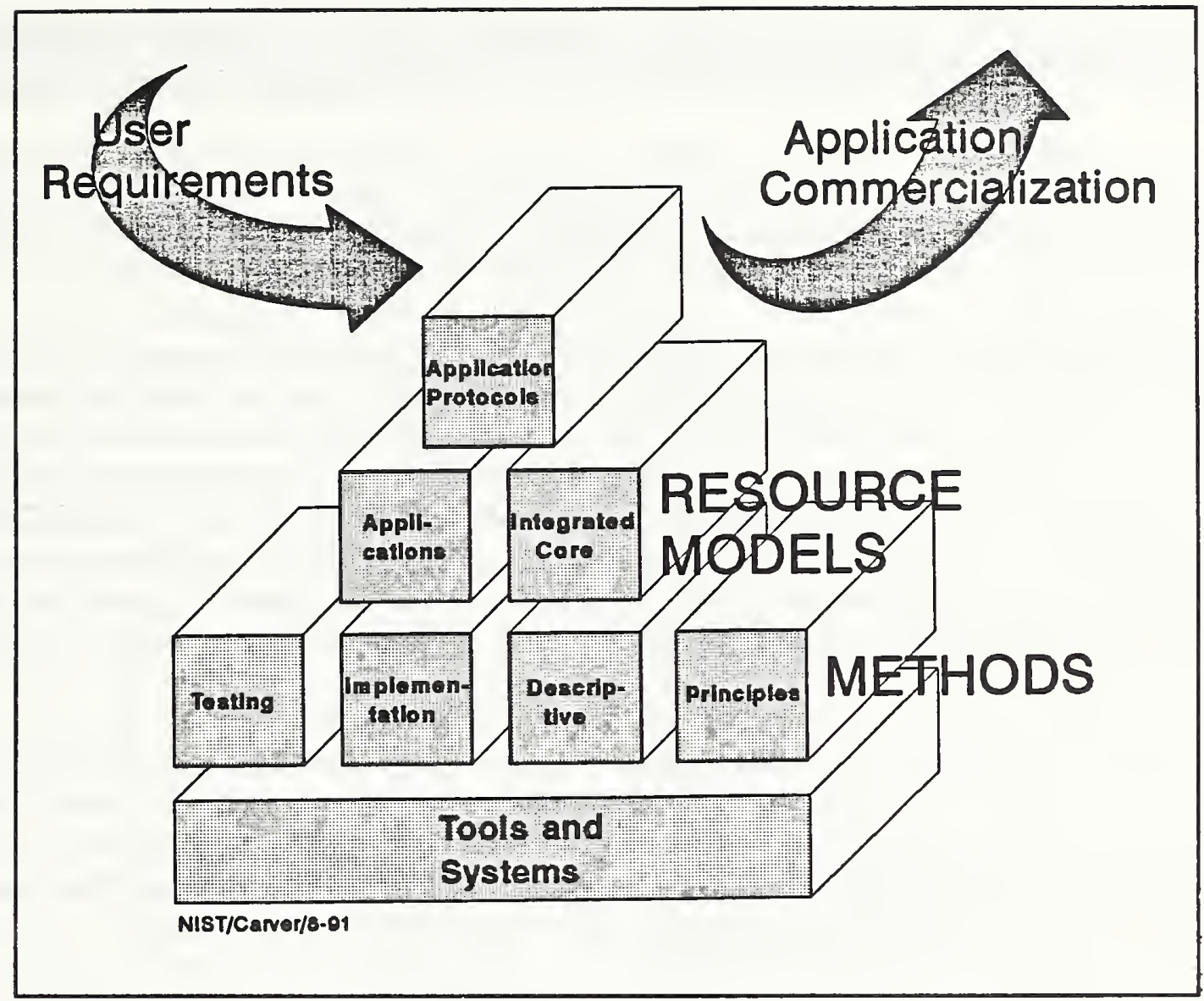

Figure 1-3. Foundation of STEP.

entities across a specified set of resources (for example, tolerance and geometry) and applications (such as drafting). The APs (and in turn the resource models) are being developed according to a set of rules that are specified within four methodology categories (shown as "Methods"): Testing, Implementation, Descriptive, and Principles. For each method, there is a corresponding set of Parts. The collection of APs, resource models and methods make up the evolving STEP standard.

Testing methods define the requirements and procedures for the verification, validation, and conformance testing of the emerging standards and the resulting system implementations.

Implementation methods define the means in which the information expressed through the standard is actually managed when it is implemented in a real application. The STEP effort defines four levels of implementation: File Exchange, Working Form, Shared Database, and Knowledge Base.

Descriptive methods define the manner in which the standard is specified. Information modeling is the key method, and a special object-oriented information-modeling language, EXPRESS, is to become a standard itself. 
Principles methods are the basic set of requirements and scope for the development of the entire set of STEP parts.

The bottom block, "Tools and Systems," is not part of the actual standard, but instead provides support functions for the standards activities. Included in this category are items such as configuration management systems, qualification and integration of parts, software tools such as editors and compilers, and the computer support systems.

The STEP strategy is to define a framework for classifying application protocols so that a "roadmap" for implementing STEP can be published that describes levels of functionality (in terms of the product life cycle, product type, and other criteria). The first version of STEP will have, as a minimum capability, the file exchange for drafting information (where tolerancing and dimensioning are considered symbols uncoupled from part geometry). Additional APs being considered are: file exchange for associative drafting, in which tolerancing and dimensioning must change as a part's geometry changes; configuration control of design data; mechanical design using boundary representation; and mechanical design using surface representation.

After this first version, strong consideration will be given to producing a collection of APs that replace all the functionality of the mechanical aspects of IGES. Further down the road will be the set of APs needed to manufacture a mechanical part. Over FY92, the STEP community should have a structured approach to STEP versions. This is also to be coordinated through the National Initiative for Product Data Exchange. 


\title{
2.0 Management and Administrative Support
}

\begin{abstract}
W ITH THE ARRIVAL OF the new fiscal year came the departure of the National PDES Testbed's Project Manager, Charles R. (Chuck) McLean. McLean, who had served as manager since 1989, chose to return to his role as a Senior Staff Engineer to conduct independent research. In his absence, project management was assumed by the Chief of NIST's Factory Automation Systems Division, Howard M. Bloom. The Project Management office, meanwhile, continued to perform all administrative duties, such as budget, scheduling, and tracking.
\end{abstract}

New Project Manager Chosen: After an extensive search, a replacement for McLean was found. Ms. S. Jeane Ford will join NIST and the National PDES Testbed in April. Ford, a private consultant in Santa Clara, California, has spent 18 years researching, developing, and managing programs in product data systems. In addition to having served on PDES technical advisory groups and industry review boards, she will bring to the project 14 years' experience at DoD prime contractors.

Technical Writer/Editor Arrives: As STEP's development pace has increased, so has the need to create reports, manuals, and presentations that clearly explain testing efforts, the software elements, and their significance to CALS. Toward this end, in October the three members of the Project Management office were joined by a full-time technical writer/editor. For 11 years, Paul F. Stregevsky wrote, edited, and managed reports, presentations, procedures, and articles on computer-integrated manufacturing systems for DoD prime contractors. His participation is expected to help the Testbed meet the DoD's objectives for transferring STEP technology to industry. 
National PDES Testbed-1Q92 Status Report 


\title{
3.0. Travel Coordination and Operational Support
}

\begin{abstract}
$\mathbf{T}$
ECHNICAL DEVELOPMENT continued to require frequent across-the-table exchanges with colleagues in industry, Government, academia, and the standards communities. Hence, extensive travel remained a fact of life. Back at the Testbed, the variety and continuous state of change in software, computers, interfaces, and users required daily technical support.
\end{abstract}

\subsection{Travel Coordination}

At off-site gatherings, Testbed members exchanged findings and expertise, negotiated criteria and goals, and helped ensure that STEP will meet DoD's needs.

In 1Q92, the Testbed sponsored 29 working trips. Two week-long working meetings-CALS Expo '91 and the joint meeting of IPO and ISO-accounted for most of the quarter's travel expenses; for details of the Testbed's participation at CALS Expo '91, see Sections 8.1 through 8.3. Trips taken during $1 \mathrm{Q} 92$ are listed, together with their contribution toward PDES or STEP, in Table 3-1.

For a discussion of the rationale for setting travel priorities in support of the development of STEP, see Section 5.1, "IPO/ISO Support."

Note: Six Testbed members chair committees or working groups for IPO or ISO. When their groups convene, their travel is funded either by the Testbed or by non-Testbed funding. To reduce costs, interim meetings are often held at NIST, sparing them the need to travel.

\subsection{Testbed Computer Support (TCS)}

1Q92 marked the first full quarter for this project. Work continued toward isolating the Testbed computers from the part of the network that links the other computers in the host Division (Factory Automation Systems). This isolation will ensure that the Testbed keeps running and that its data remains secure, should a failure occur in one of the Division's computers or the network itself.

The Testbed computing environment is designed to be heterogeneous. Hence, a good deal of time was devoted to trouble-shooting network hardware and software already being used by Testbed personnel and installing new hardware and networking software.

In November, the TCS staff enhanced the functionality of the Validation Testing Laboratory in time for NIST's 1991 Automation Open House (discussed in Section 8.6). They set up the demonstrations and ensured that the Laboratory was operational before 
each demonstration began. During the Open House, visitors were guided by screen menus designed by the TCS project manager.

\begin{tabular}{|c|c|c|c|}
\hline When? & Where? & Who? & Why? \\
\hline $\begin{array}{l}30 \text { Sept.- } \\
04 \text { Oct. }\end{array}$ & $\begin{array}{l}\text { CDIM A2 meeting } \\
\text { (Palo Alto) }\end{array}$ & $\begin{array}{l}\text { Allison } \\
\text { Barnard }\end{array}$ & $\begin{array}{l}\text { to represent the Testbed core-team meeting, } \\
\text { review issues written against the AP } 201 \\
\text { Application Reference Model (ARM), and } \\
\text { review all issues against AP } 202 \text { ARM }\end{array}$ \\
\hline 01-03 Oct. & $\begin{array}{l}\text { Sheet-Metal Project } \\
\text { Test Team meeting } \\
\text { (Troy, Mich.) }\end{array}$ & $\begin{array}{l}\text { Kevin } \\
\text { Jurrens }\end{array}$ & $\begin{array}{l}\text { to lead the Sheet Metal Project Test Team in } \\
\text { the final test-issues meeting for Version } 0.3 \text { of } \\
\text { CDIM SM1. }\end{array}$ \\
\hline \multirow[t]{9}{*}{ 20-24 Oct. } & \multirow[t]{9}{*}{$\begin{array}{l}\text { ISO/IPO quarterly } \\
\text { meeting (Houston) }\end{array}$} & $\begin{array}{l}\text { Allison } \\
\text { Barnard }\end{array}$ & $\begin{array}{l}\text { to meet with WG3 (Drafting) to discuss \& co- } \\
\text { ordinate progress on APs } 201 \text { ( } 2 \text { D Drafting) \& } \\
202 \text { (Associative Draft.); participate in meet- } \\
\text { ings on AP Guidelines \& Conform. Testing }\end{array}$ \\
\hline & & Steve Clark & $\begin{array}{l}\text { to present a talk to Express Users' Group '91 } \\
\text { workshop; attend meetings of ISO's Express } \\
\text { Project }\end{array}$ \\
\hline & & $\begin{array}{l}\text { Jesse } \\
\text { Crusey } \\
\end{array}$ & $\begin{array}{l}\text { to participate in meetings of CDIM B4 team } \\
\text { and Shape Tolerance Committee }\end{array}$ \\
\hline & & Shaw Feng & $\begin{array}{l}\text { to represent Testbed in Shape Tolerance } \\
\text { Committee and help complete draft of Part } 47 \\
\text { (Shape Tolerance Models) }\end{array}$ \\
\hline & & Jim Fowler & $\begin{array}{l}\text { to attend meetings of WG7 (Implementation } \\
\text { Specs) }\end{array}$ \\
\hline & & $\begin{array}{l}\text { Cita } \\
\text { Furlani }\end{array}$ & $\begin{array}{l}\text { to represent Testbed on PDES, Inc. System } \\
\text { Integration Board; present Testbed status re- } \\
\text { port to Gen. Assem./Plenary; attend meetings, } \\
\text { including U.S. Tech. Advisory Group (TAG) }\end{array}$ \\
\hline & & $\begin{array}{l}\text { Sharon } \\
\text { Kemmerer }\end{array}$ & $\begin{array}{l}\text { to resolve the first Committee Draft ballot } \\
\text { comments on Part } 31 \text { (Framework and General } \\
\text { Concepts for Conformance Testing) }\end{array}$ \\
\hline & & $\begin{array}{l}\text { Mary } \\
\text { Mitchell }\end{array}$ & $\begin{array}{l}\text { to attend meetings of WG4 (Qualifica- } \\
\text { tion/Integration), WG6 (Conformance } \\
\text { Testing), \& U.S. TAG; and present training } \\
\text { plan to PMAG \& Academic Liaison meetings }\end{array}$ \\
\hline & & $\begin{array}{l}\text { Sandy } \\
\text { Ressler }\end{array}$ & $\begin{array}{l}\text { to attend meetings of WG6 (Conformance } \\
\text { Testing); coordinate with ITI on conformance } \\
\text { testing; attend technical publications committee }\end{array}$ \\
\hline
\end{tabular}




\begin{tabular}{|c|c|c|c|}
\hline When? & Where? & Who? & Why? \\
\hline 29-30 Oct. & $\begin{array}{l}\text { PDES, Inc. meeting } \\
\text { (Troy, Mich.) }\end{array}$ & $\begin{array}{l}\text { Kevin } \\
\text { Jurrens }\end{array}$ & $\begin{array}{l}\text { to participate in the final meeting of the CDIM } \\
\text { SM1 effort of the Sheet Metal Project }\end{array}$ \\
\hline \multirow[t]{9}{*}{$\begin{array}{l}11-14 \\
\text { Nov. }\end{array}$} & \multirow[t]{9}{*}{$\begin{array}{l}\text { CALS Expo '91 } \\
\text { (Phoenix) }\end{array}$} & $\begin{array}{l}\text { Howard } \\
\text { Bloom }\end{array}$ & to give a presentation on Testbed \\
\hline & & $\begin{array}{l}\text { Cita } \\
\text { Furlani }\end{array}$ & $\begin{array}{l}\text { to lead the track, "Standards \& Testing: Com- } \\
\text { peting in a Global Market," \& attend Industry } \\
\text { Steering Group's Standards Working Group }\end{array}$ \\
\hline & & $\begin{array}{l}\text { Clarence } \\
\text { Johnson }\end{array}$ & $\begin{array}{l}\text { to coordinate materials and help run the } \\
\text { Testbed booth }\end{array}$ \\
\hline & & $\begin{array}{l}\text { Mary } \\
\text { Mitchell }\end{array}$ & $\begin{array}{l}\text { to give presentations on STEP toolkits and } \\
\text { validation testing and help run the IPO booth }\end{array}$ \\
\hline & & $\begin{array}{l}\text { Mark } \\
\text { Palmer } \\
\end{array}$ & $\begin{array}{l}\text { to give a presentation on AP methodology and } \\
\text { discuss projects relevant to the AP Framework }\end{array}$ \\
\hline & & $\begin{array}{l}\text { Julie } \\
\text { Parker }\end{array}$ & $\begin{array}{l}\text { to set up and operate the interactive } \\
\text { multimedia tutorial and answer users' } \\
\text { questions about it }\end{array}$ \\
\hline & & Bill Burkett & \multirow{3}{*}{$\begin{array}{l}\text { to lead sessions of tutorial, STEP and the } \\
\text { PDES Activities }\end{array}$} \\
\hline & & Jack Skeels & \\
\hline & & $\begin{array}{l}\text { Chuck } \\
\text { Stark }\end{array}$ & \\
\hline 11-15 Nov. & $\begin{array}{l}\text { PDES, Inc. CDIM } \\
\text { A2 meeting (Dallas) }\end{array}$ & $\begin{array}{l}\text { Allison } \\
\text { Barnard }\end{array}$ & $\begin{array}{l}\text { to represent Testbed at the CDIM A2 core- } \\
\text { team meeting, discuss issues raised against the } \\
\text { CD version of Part 101, and develop an } \\
\text { AP202 (Associative Draft.) Testing Proj. Plan }\end{array}$ \\
\hline 12 Nov. & $\begin{array}{l}\text { AUTOFACT'91 } \\
\text { (Chicago) } \\
\end{array}$ & Shaw Feng & $\begin{array}{l}\text { to learn about latest developments in } \\
\text { CAD/CAE/CAM/CIM software }\end{array}$ \\
\hline 17-23 Nov. & $\begin{array}{l}\text { PDES Inc. team } \\
\text { meeting (San Diego) }\end{array}$ & $\begin{array}{l}\text { Jesse } \\
\text { Crusey } \\
\end{array}$ & $\begin{array}{l}\text { to continue work on the Applic. Activ. Model } \\
\text { (AAM) for "Process Plan. for N/C" AP }\end{array}$ \\
\hline 2-3 Dec. & $\begin{array}{l}\text { University of Florida } \\
\text { (Gainesville) }\end{array}$ & Steve Clark & $\begin{array}{l}\text { to attend demos of an integrated environment } \\
\text { for databases and learn about U. of Florida's } \\
\text { research in information-model translation }\end{array}$ \\
\hline 2-6 Dec. & $\begin{array}{l}\text { PDES, Inc. CDIM } \\
\text { A2 meeting (Ft. } \\
\text { Collins, Col.) }\end{array}$ & $\begin{array}{l}\text { Allison } \\
\text { Barnard }\end{array}$ & $\begin{array}{l}\text { to represent Testbed at CDIM A2 core-team } \\
\text { meeting, finalize the AP202 (Associative } \\
\text { Drafting) Testing Project Plan, \& begin } \\
\text { developing the AP202 Test Plan }\end{array}$ \\
\hline
\end{tabular}




\begin{tabular}{|c|c|c|c|}
\hline When? & Where? & Who? & Why? \\
\hline 8-13 Dec. & $\begin{array}{l}\text { PDES, Inc. Meeting } \\
\text { (Dallas) }\end{array}$ & $\begin{array}{l}\text { Jesse } \\
\text { Crusey }\end{array}$ & $\begin{array}{l}\text { to continue developing the applic. activ. model } \\
\text { (AAM) for "Process Planning for N/C" AP }\end{array}$ \\
\hline 17-19 Dec. & $\begin{array}{l}\text { DEC's CAD/CAM } \\
\text { Technology Division } \\
\text { (Chelmsford, Mass.) } \\
\end{array}$ & Jim Fowler & $\begin{array}{l}\text { to resolve issues raised at a PDES, Inc. SDAI } \\
\text { meeting }\end{array}$ \\
\hline 18-19 Dec. & $\begin{array}{l}\text { PDES, Inc. Common } \\
\text { Methods Meeting } \\
\text { (Long Beach) }\end{array}$ & $\begin{array}{l}\text { Mary } \\
\text { Mitchell }\end{array}$ & $\begin{array}{l}\text { to present the Validation Testing position on } \\
\text { CDIM and AP Testing Methodology and to } \\
\text { determine its impact on software tools }\end{array}$ \\
\hline
\end{tabular}


$\mathrm{O}_{\mathrm{r}}$ F THE FIVE TESTBED PROJECTS designed to address DoD-specific STEP requirements, only one-the framework project for application protocols (APs)-continued to receive DoD funding. Of the remaining four projects, one-AP for Inspection Planning-was funded by NIST; the Institute regards this project as critical, because deferring it would hold up completion of APs already in development, including the tolerancing resource model. In addition, the Inspection Planning AP was considered a critical one for NIST to lead because NIST personnel serve on key tolerancing standards committees, both domestic and international.

The other three de-funded projects were placed on hold. NIST believes, however, that all three are key STEP efforts for which NIST should maintain the technical lead, for reasons cited in the FY92 Statement of Work. Hence, new funding alternatives are being explored.

\subsection{AP Framework and Methodology}

At defense plants and military depots, end users have requirements for implementing systems that use the STEP methodology. These requirements are converted to Application Protocols, referred to as $A P s$, that define three sets of data:

- an application's scope-for example, process planning for machined mechanical parts

- the information to be exchanged between the application and a data repository, such as a file or a shared database

- conformance specifications to help the developers of STEP-based applications implement the AP correctly.

APs become subsets of STEP that systematically increase its capability. The methodology for developing APs is rather complex; a more detailed treatment can be found in the National PDES Testbed FY92 Statement of Work.

1Q92 marked the start of the AP Framework and Methodology project. As the accomplishments suggest, it was a quarter of charting direction and forging ties in the PDES and CALS communities:

- Requirements Defined-Initial requirements for the AP Framework were defined. 
- Plan Approved-The AP Framework Project Plan was developed and presented-together with the initial requirements-to IPO and to the Project Management Advisory Group (PMAG) of ISO's TC184/SC4-that is, Technical Committee 184 (Industrial Automation Systems), Subcommittee 4 (Industrial Data and Global Manufacturing Programming Languages). The PMAG agreed that the framework is needed and approved the development plan.

- Guidelines Approved for Release-Version 0.9 of Guidelines for the Development and Approval of STEP Application Protocols was distributed for review and approval by the working groups (WGs) of the STEP Subcommittee. All comments were resolved. Then the WG conveners approved the Guidelines for release. Version 1.0 was to be distributed in January for use by the DoD/CALS organization, the IGES/PDES Organization (IPO), ISO, and other organizations involved with product data standards.

- Palmer Named STEP AP Coordinator-Mark Palmer, who manages the AP Framework and Methodology project for the National PDES Testbed, was appointed by Subcommittee 4's Project Management Advisory Group to be the AP Coordinator for STEP.

- Similar Projects Studied-To avoid duplication of effort, Palmer conducted an initial study of projects whose scope suggested they might be relevant to the AP framework. His study comprised some two dozen projects being funded under a variety of domestic, European, and global auspices, both public and private.

- Expoers Learn ABCs of APs-At CALS Expo '91, Palmer gave a presentation covering the AP methodology, current PDES/STEP AP projects, and AP technical issues.

The major milestones for this project are shown below in Figure 4-1.

\begin{tabular}{|c|c|c|c|c|c|c|c|c|c|c|}
\hline \multirow{2}{*}{ Activities } & \multicolumn{2}{|c|}{1981} & \multicolumn{8}{|c|}{1982} \\
\hline & $\mathbf{O} \mathbf{N}$ & o & J & $F / M$ & A & M & J & J & A & $s$ \\
\hline \multicolumn{11}{|l|}{ APFu 1.0 Dovelop Application Protocol Framework } \\
\hline \multicolumn{11}{|l|}{ Roport, "Plenning Franework for STEP Application Protocols" } \\
\hline \multicolumn{11}{|l|}{ APFM 20 Recommond Procedurea/Criterla for Evaluating STEP AP Projocts } \\
\hline \multicolumn{11}{|l|}{ Roport, "Recommonded Procedures and Criteria for Evaluating STEP AP Prolects" } \\
\hline \multicolumn{11}{|l|}{ APFU 3.0 Present a Summary of Current AP Methodology and Guidelines } \\
\hline \multicolumn{11}{|l|}{ Technical Presentation, "Overvlow of the STEP Application Protocol Methodology" } \\
\hline \multicolumn{11}{|l|}{ APFM 4.0 Rovise Guidolines for STEP AP Development and Approve } \\
\hline Ropor, "Guldelines for the Development and Approval of STEP Application Protocols, Verelon 1.1" & & & & & & & & & & \\
\hline
\end{tabular}

Figure 4-1. Major Milestones for AP Framework and Methodology. 


\subsection{Application Protocol for Inspection Planning (NIST-Funded)}

In 1Q92-this project's first quarter-the staff submitted a project plan, completed Task 1 , and established strong working ties with industry through PDES, Inc.

- Completed Task 1: "Compare Part 47 Draft with Y14.5.1 and DMIS"-The draft of STEP Part 47 (Shape Tolerance Model) was compared with related standards-three from ANSI (including one in draft form), eight from ISO. (The names of these 11 standards can be found in Table A-1, located in the Appendix.) With the differences in hand, the findings were documented in a series of tables; a sample appears below in Table 4-1. The tables, with discussions of their significance, can be found in a NIST Interagency/Internal Report (NISTIR 4744), Comparison of ISO 10303 Part 47 Draft with ANSI and ISO Tolerancing Standards for Harmonization and Completion of Part 47. The report goes on to recommend actions for the harmonization and completion of Part 47. It was scheduled to be distributed in January.

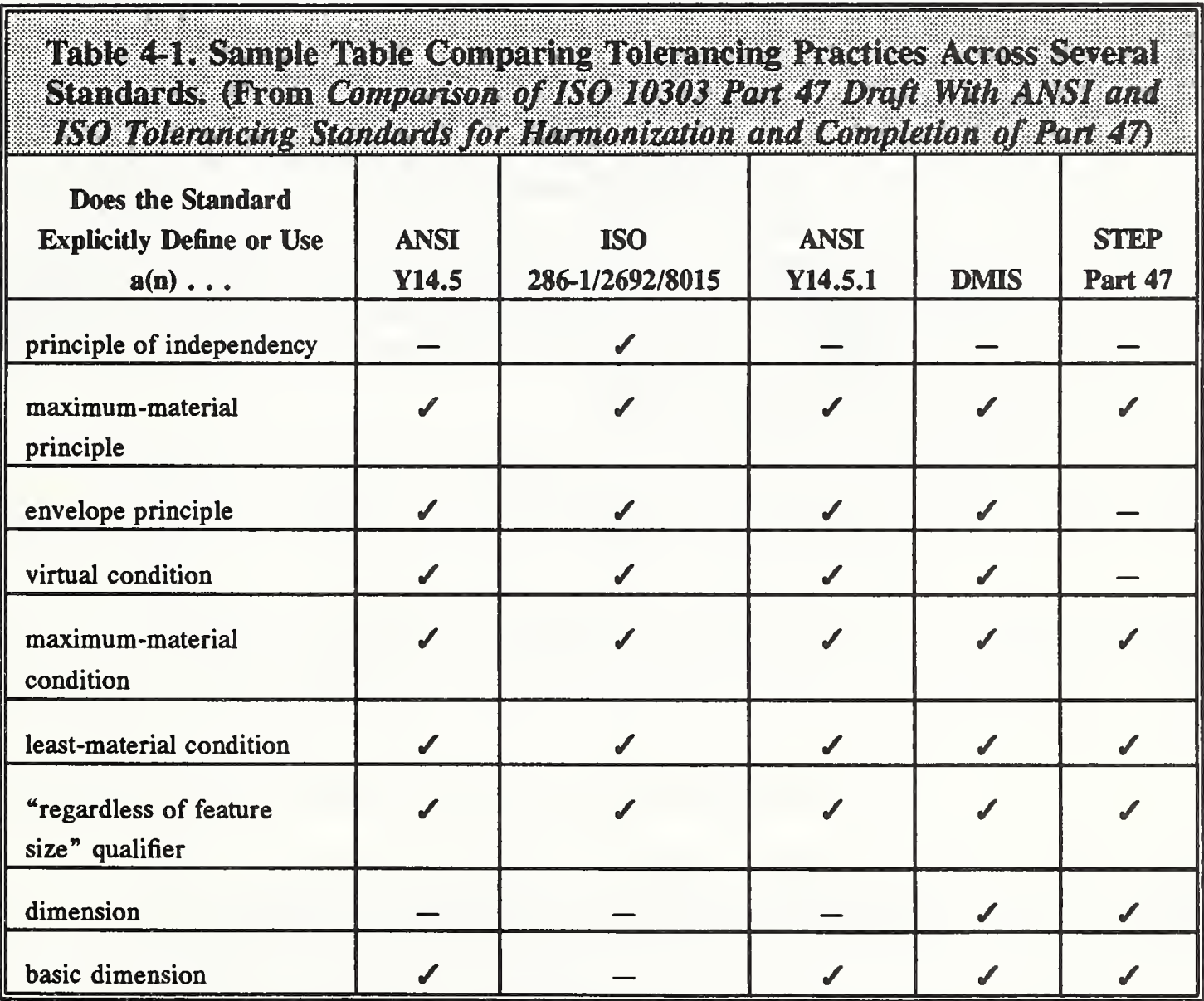

- External Working Ties Established-At the November ISO/IPO meeting in Houston, project team Shaw Feng and Jesse Crusey established solid working relationships with other committee members and other participants. 
- Trans-Atlantic Cooperation Arranged-While in Houston, Feng and Crusey met with their European counterparts from the German VIMP project (Visionbased on-line Inspection of Manufactured Parts), which is funded by ESPRIT (European Strategic Programme for Research in Information Technology). Since the projects share common goals, the two teams orally agreed to work together to develop STEP's Application Protocol for Inspection Planning.

\subsection{Three Projects Placed on Hold}

Because the Testbed's budget was reduced, three Testbed projects were placed on hold:

Application Protocol for Process Planning-This project would have identified and documented information found in commercial process-planning systems. From the findings, an AP was to have been developed to automate the process planning of mechanical parts. The plan called for STEP files to be generated at one site and passed to others, where they would be used to create process plans or to machine parts.

Product Data Exchange Network (PDEN) - This network was to consist of manufacturing sites and research centers from government, industry, and academia, linked over existing networks. Such a network was expected to test STEP in a more thorough and meaningful way than would be possible if testing took place in the Testbed alone.

STEP Production Cell (SPC) - This project was aimed at implementing prototypes of the systems needed to design and produce STEP-based mechanical parts in a real-world environment. As in PDEN, the various cells would have been dispersed across the country, with STEP data being exchanged. 
IN THESE TWO PROJECTS, the Testbed serves as a fulcrum of talent and information, leveraging the technical capabilities of the standards community. Though lacking the glamor of development projects, IPO/ISO Support and Configuration Management play critical value-added roles for the entire PDES effort.

\subsection{IPO/ISO SUPPORT (IIS)}

Efforts focused on identifying which NIST staff would be supported by this project to provide the most effective participation in IPO and ISO STEP development activities. Initially, the distribution of the resources of this project has been aimed toward a funding level of 25 percent for chairpersons of ISO or IPO projects and of 15 percent for technical contributors to ISO or IPO projects. Trips required by ISO and IPO project leaders are funded either by other Testbed projects or by non-Testbed auspices. In many cases, technical contributors who do not hold leadership roles do not have to travel, because interim meetings often are held at NIST. However, there will always be a need for more support than can be committed. Priorities are being based on the direct benefit to DoD and the defense industry, as well as on how best the Testbed's expertise can be leveraged.

The IIS manager worked from a list with initial priorities. This section reports on the support provided from that list. In addition to the work directly supported by this project, additional Testbed leadership in the development of STEP is funded through other Testbed projects-for example, AP Framework and Methodology.

Task 1: Support ISO Development Activities-At quarter's end, 11 NIST contributors to ISO projects were candidates for support from this project. They are listed in Table A-2 (found in the Appendix).

During this quarter, Testbed staff supported by this project have . . .

- continued serving as Convener of WG5, "STEP Development Methods," and Co-Chair of "IPO PDES Development Methods"-These committees are closely related, ensuring that the work done in IPO and ISO is cohesive and coordinated. These are critical roles for Testbed staff to perform. It is in these two groups that the Express specification language and the overall STEP architecture are being developed.

- provided Co-chairs for and developed a Training Plan for STEP developers and users-The Plan focuses on the immediate need to educate individuals 
furnished from projects as resources who can qualify and integrate modules for all of STEP. This integration task is the primary "single point of failure" in STEP's development. It is also, however, a task most of whose work can be performed simultaneously, if enough trained people are available to do the work. By providing leadership for this project, Testbed management ensures that the training requirements for validation and conformance testing will be supported.

- assumed the Chair of the Qualification and Validation Project in Working Group 4-Mary Mitchell was named to assume this role. This is a critical role for Testbed staff to perform. It is the project within the STEP development activities that is defining the role of validation testing. At the IPO/ISO meeting in October, this project set its priorities and continued its work on the qualification of STEP Version 1.0 Parts. Testbed staff who participate in these STEP activities also participate in Working Group 6 (Conformance Testing), funded by non-Testbed resources, thus leveraging Testbed funds.

- assumed the Chair of the ISO Shape Tolerance Committee-Jesse Crusey, of the AP for Inspection Planning project, was elected to chair both ISO's and IPO's Shape Tolerance Committees. Project manager Shaw Feng, meanwhile, was leading the development process of Part 47 (Shape Tolerance Model) toward completion of the first version.

- supported ISO's Subcommittee on Industrial Data and Global Manufacturing Programming Languages (TC184/SC4)-It is critical that the experiences and lessons learned from the other activities of the National PDES Testbed be used to support the actual balloting on STEP Committee Drafts and Draft International Standards. Technical review of each STEP Part requires two resources: (1) time to provide written comments incorporating that review, and (2) a voting member to defend NIST's position. The initial policy of Testbed management is that the resources for balloting will be provided from the other Testbed projects. However, the IIS project has been coordinating all Testbed resources to ensure that each STEP Part is reviewed, and that the comments are incorporated in the NIST ballot sent to the U.S. Technical Advisory Group.

- served as Editor of STEP Part 22, STEP Data Access Interface.

Task 2: Support IGES/PDES Organization (IPO) Technical Activities-NIST personnel hold lead roles in five IPO projects that are candidates for receiving funding from the IIS project; they are listed in Table A-3 (found in the Appendix).

In 1Q92, Testbed staffers accepted the roles of Chair of the IPO Tolerance Committee and Owner of STEP Part 47, Shape Tolerance. That Part was developed by this committee and now is being reviewed and improved, under the auspices of ISO. Testbed staff that participate in these STEP activities also participate in ISO/TC10 (Technical Drawings, Product Definition, and Related Documentation), funded by non-Testbed 
resources. The dual leadership by Testbed staff ensures that the these two international standards efforts receive the coordination they require. This coordination, in turn, will assure that defense-industry requirements are supported by this Part.

A Testbed member continued chairing the Committee, "IPO STEP Implementation Specifications. This chair is a critical role for Testbed staff to perform. If NIST leadership is replaced by a person from U.S. industry, the committee's agenda and output work may be viewed as products of self-interest over community interest. Testbed leadership of this committee, coupled with strong participation in Working Group 7 (of the same name), will ensure that defense industry requirements are supported by the STEP Data Access Interface (SDAI). That Part is the basis for the actual implementation of STEP-based systems.

Several members of the Testbed staff are technical contributors to the specification of SDAI. Once again, these same individuals are funded by non-Testbed resources to contribute to the development of related information technology standards. Thus, their contributions to STEP through Testbed funding can leverage that expertise.

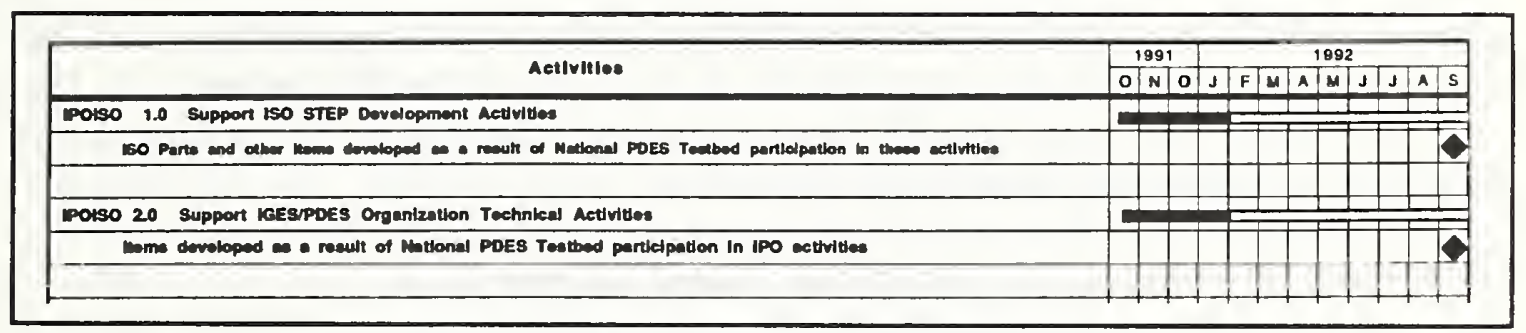

Figure 5-1. Major Milestones for IPO/ISO Support.

\subsection{Configuration Management Systems and Services (CMS\&S)}

Throughout STEP's development, thousands of documents and computer programs must be created and managed. It is critical that users know whether a given version is up-todate. Through configuration management, these documents and programs are being tracked and maintained for IPO, ISO, the National PDES Testbed, and PDES, Inc.

Task 1: Define, Plan, and Track Project-The Configuration Management Systems and Services Development Plan: Revised Edition was distributed to the CM team members for review. The Plan was submitted to the NIST Information Systems Group Leader.

The Configuration Management Comprehensive Requirements Document was reviewed, revised, and provided to the Integrated Systems Group Leader for technical review. At the end of December, formal review was still underway, but general comments appeared favorable.

Task 2: Enhance STEP On-Line Information Service (SOLIS)-The Procedures Guide was completed and began to undergo review and test.

SOLIS was enhanced in three ways: 
- Downloadable copies of the indexes no longer have to be maintained manually; they are updated automatically.

- Security for SOLIS was upgraded. Further restrictions on write access were put into place. A software routine was created that looks for-and flags-writable files.

- The file system now resides on dedicated disc storage. The stand-alone discs provide more storage. More important, they insulate $\mathrm{CM}$ files from problems that may arise elsewhere in the Division's computer network.

Preliminary results of a $4 \mathrm{Q} 91$ study suggested that it would be prudent to continue to provide some manner of dial-up access. While introducing the new file setup, the $\mathrm{CM}$ team began exploring the use of Kermit, a broadly used, public-domain file-transfer mechanism. Compared with the bulletin board system (BBS), Kermit features a look and feel that is more familiar to users accustomed to other SOLIS access software. Until Kermit is in place, the CM team will continue to operate the STEP BBS.

Task 3: Administer and Maintain Established Services-In December alone, 51 users requested more than 900 files from SOLIS. At the Testbed, five files were added. Users can now choose from more than 500 files to download from SOLIS. The main directories are listed in Table A-4 (found in the Appendix).

The major milestones of this project are shown in Figure 5-2.

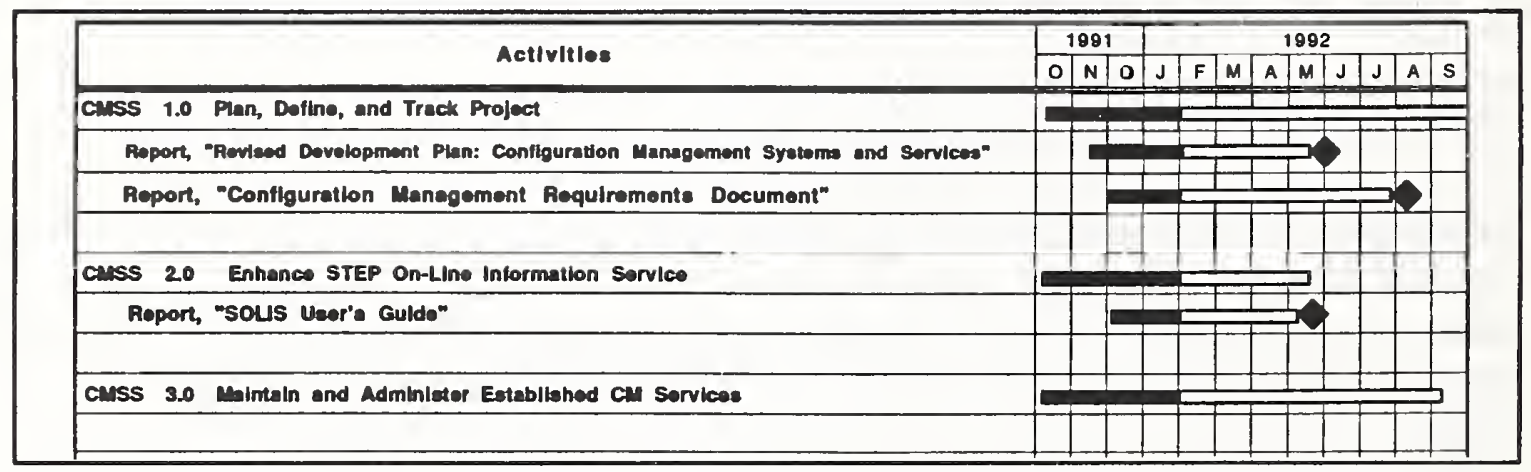

Figure 5-2. Major Milestones for Configuration Management Systems and Services.

\subsection{Noncontractual Support}

NIST's technical support for standards organizations goes beyond the coordination and assistance furnished by the National PDES Testbed. In 1Q92, much of the Institute's support took place "off line" or under other auspices. 


\subsubsection{Electrical "Harmonization" Project (NIST-Funded)}

On 10-13 December, two employees funded by NIST's Electronics \& Electrical Engineering Laboratory (EEL) participated in the Modeling Workshop of HPS, the Harmonization of Digital Product Data Standards Organization. The workshop, held in Albuquerque, was sponsored by HPS's Development Coordinating Council, under the auspices of ANSI. Portions of the workshop were held jointly with PDES, Inc.'s Electrical/Electronics Team (discussed in Section 6.5).

The HPS objective is to resolve the differences between the data models of four existing ANSI standards for electronics. Participants recognized that 400 "entities" must be harmonized at a steady pace if the complete federated data model is to appear in STEP by 1994. At the workshop, four models were correlated to the CAD Framework Initiative (CFI) model. Later, a graphic model was created for each standard and the harmonized model. The NIST employees returned with the graphic model to have it commented upon.

\subsubsection{National Initiative for Product Data Exchange (NIST-, DoD-, and Industry-Funded)}

Although this DoC Initiative would not formally begin until 6 January, the program is headquartered in the same building as most of the Testbed staff. Testbed personnel took advantage of this proximity to begin coordinating plans. For example, the National Initiative Office set its first Planning Workshop for 29-30 January, which would be held at NIST. The Testbed staff agreed to participate.

In December, the Configuration Management team submitted a proposal to conduct configuration management for the National Initiative's documents. At quarter's end, the proposal was being reviewed. 
National PDES Testbed-1Q92 Status Report

$5-6$ 


\subsection{Technical Coordination With Industry}

\subsection{PDES, Inc. Technical Program Support}

Six members of the Testbed technical staff devoted a portion of their time to support PDES, Inc. technical efforts in eight areas:

- Drafting Application Protocol-A Testbed member was actively involved as a member of the PDES, Inc. team developing Application Protocol 202-Associative Drafting.

- Testing and Validation-The manager of Testbed Readiness and Support was working to formally test and validate software to support the testing of STEP Version 1.0.

- Refining Methods-A staff member represented NIST at PDES, Inc.'s Common Methods meeting.

- CDIM (Context-Driven Integrated Model) B-A NIST employee was helping to develop several manufacturing applications that require the accurate vertical transfer of product data. In one such application, 3-D product-design data from wireframe and surface models will be transferred intact to NC programming systems and to tool-design systems. This effort will lay the groundwork for the development of STEP application protocols.

- $T C$-CDIM B-The same employee was working with PDES, Inc. to develop the testing criteria (TC) for the manufacturing applications.

- STEP Data Access Interface (SDAI) Specification-Two Testbed members were participating in PDES, Inc.'s effort to develop and test the SDAI specification. (See also Section 6.4.)

- Systems Integration Board-The Testbed's manager of STEP Implementation Tools served as NIST's representative to PDES, Inc.'s Systems Integration Board.

- Technical Development Management-Testbed project managers reviewed PDES, Inc. documentation and reports; monitored the progress of working groups; conducted data and configuration management; and coordinated PDES activities with related organizations.

Major milestones for this project are illustrated in Figure 6-1. 


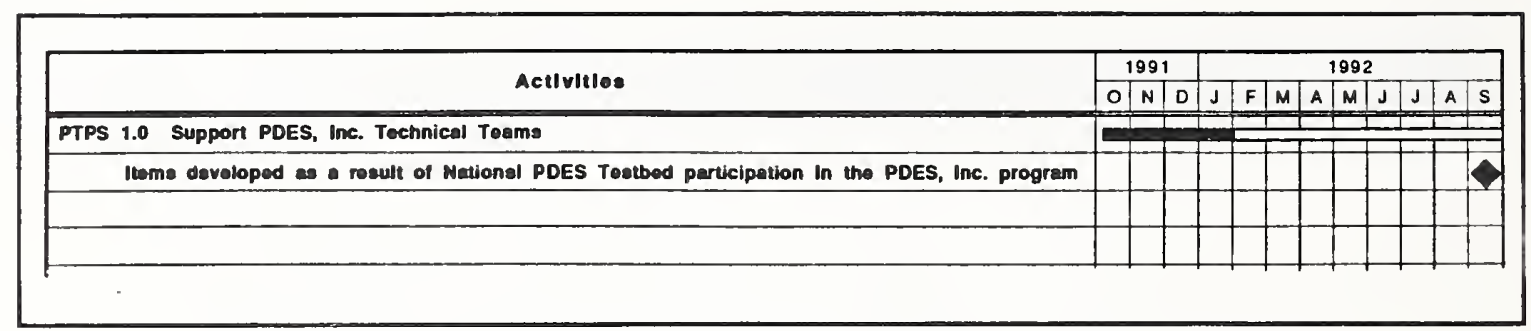

Figure 6-1. Major Milestones for PDES, Inc. Technical Program Support.

\subsection{Testbed Readiness and Support}

Significant activity occurred in four tasks.

- Task 1: Software Acceptance Testing-In October, the PDES, Inc. Block Point Release (BPR) 2.3 executables for the DECstations were installed. This installation has made an updated version of the STEP testing tools available to Testbed users. In November, the BPR 2.3 executables for SPARCstations passed Phase I testing. The SPARCstation executables are awaiting Phase II testing by PDES, Inc. before being installed for generally availability.

- Task 2: Database Administration-In October, a new database instance was created on the SPARCstation. Now, software developers from PDES, Inc. can test software that is used with the ORACLE databases.

- Task 3: Unix Environment Development-Prior to 1Q92, only one version of the Express parser at a time was available to users. In 1Q92, at the request of PDES, Inc. team members and managers, the staff of Testbed Readiness and Testbed Support redesigned certain directories to make both the established Express parser, N496 (from BPR 2.3) and the new version, N14 (to be released in BPR 3.1) concurrently available. (Previously, remote users requiring one version had to wait until users of the other version were finished.)

- Task 4: PDES Testbed Hotline-Remote users made 20 requests for help from the Testbed Hotline. Fourteen of the problems were either resolved and fixed or forwarded to the appropriate place where an answer could be found or task performed. Of the remaining six, one was solved but not fixed, three seemed to be intermittent communications problems (not easily tracked down), and two were being investigated. None of the six requests was critical.

Major milestones for this project are illustrated in Figure 6-2.

\subsection{PDES, Inc. Liaison}

By definition, the job of the PDES, Inc. liaison is not routine. But in $1 \mathrm{Q} 92$, in the absence of a Testbed Project Manager, the liaison wore more hats than usual. He . . . 


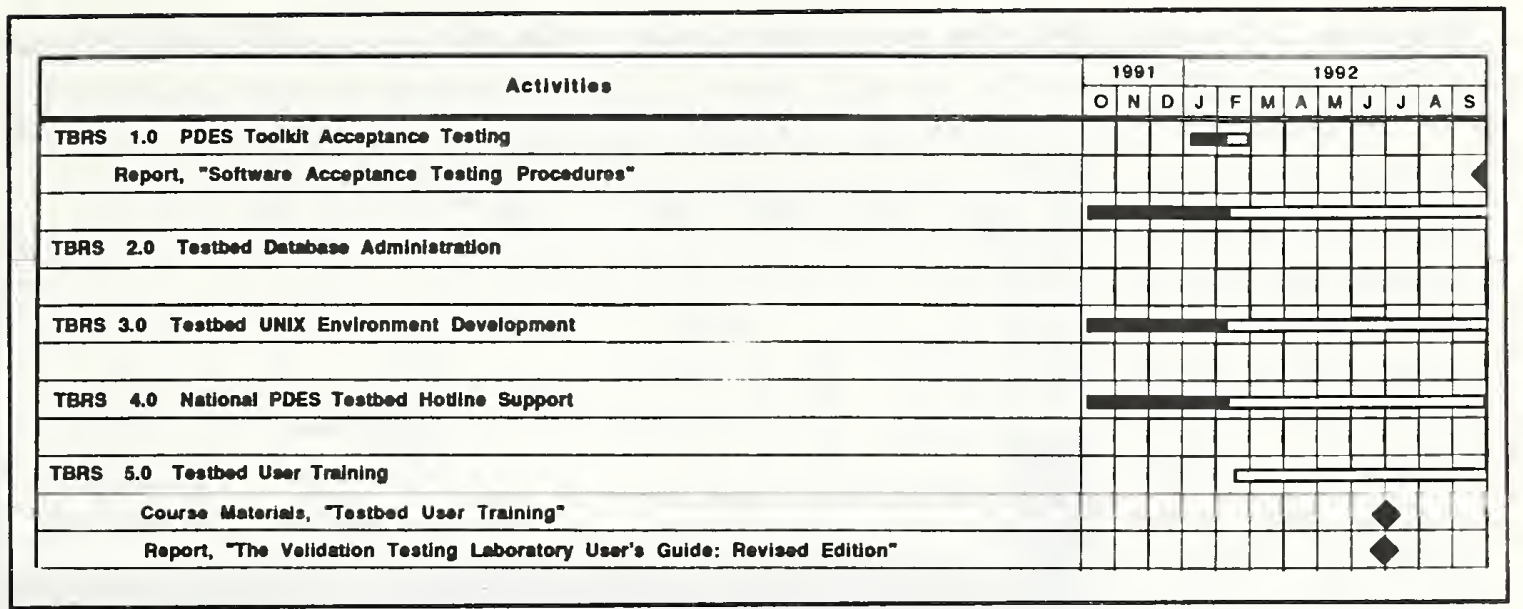

Figure 6-2. Major Milestones for Testbed Readiness and Support.

- participated in two meetings of IPO; two meetings of PDES, Inc.'s Systems Integration Board; a PDES, Inc. Technical Advisory Committee at PDES, Inc. 's headquarters (South Carolina Research Authority); and the various track sessions conducted at CALS Expo '91.

- at the request of the acting Testbed Project Manager, organized and chaired the weekly project-management team meetings.

- developed (in cooperation with PDES, Inc. technical staff) a tutorial, STEP and the PDES-Related Activities, and taught it at CALS Expo '91; details can be found in Section 8.3.

- manned Expo exhibits for NIST, IPO, and PDES, Inc.

- $\quad$ provided training for Testbed users in AP 203 (Configuration Control).

- coordinated the SDAI demonstration by DEC (discussed below in Section 6.4).

- coordinated an SDAI team meeting held at NIST.

Note: This project was funded for the first quarter only. The liaison has been reassigned to the National Initiative Office.

\subsection{STEP Data Access Interface Demonstrated by DEC}

On 11 December, the Testbed hosted a team from Digital Equipment Corporation's (DEC)'s CAD/CAM Technology Division (Chelmsford, Massachusetts). The team came to demonstrate that DEC's prototype Level-3 STEP Data Access Interface (SDAI) complied with the STEP specifications. SDAI is one of STEP's most critical components for product data exchange; DEC's SDAI software takes advantage of object-oriented 
technology-an approach that promises to vastly reduce the cost of developing and maintaining software.

In their demonstration, team members showed how two or more applications, using DEC's SDAI prototype implementation, could access and share STEP data from a single database (Figure 6-3), using a common interface.

The visitors also d e mon s trated DEC's STEP IRDS prototype; it, too, is based on objectoriented technology. The prototype showed how STEP schemas and data

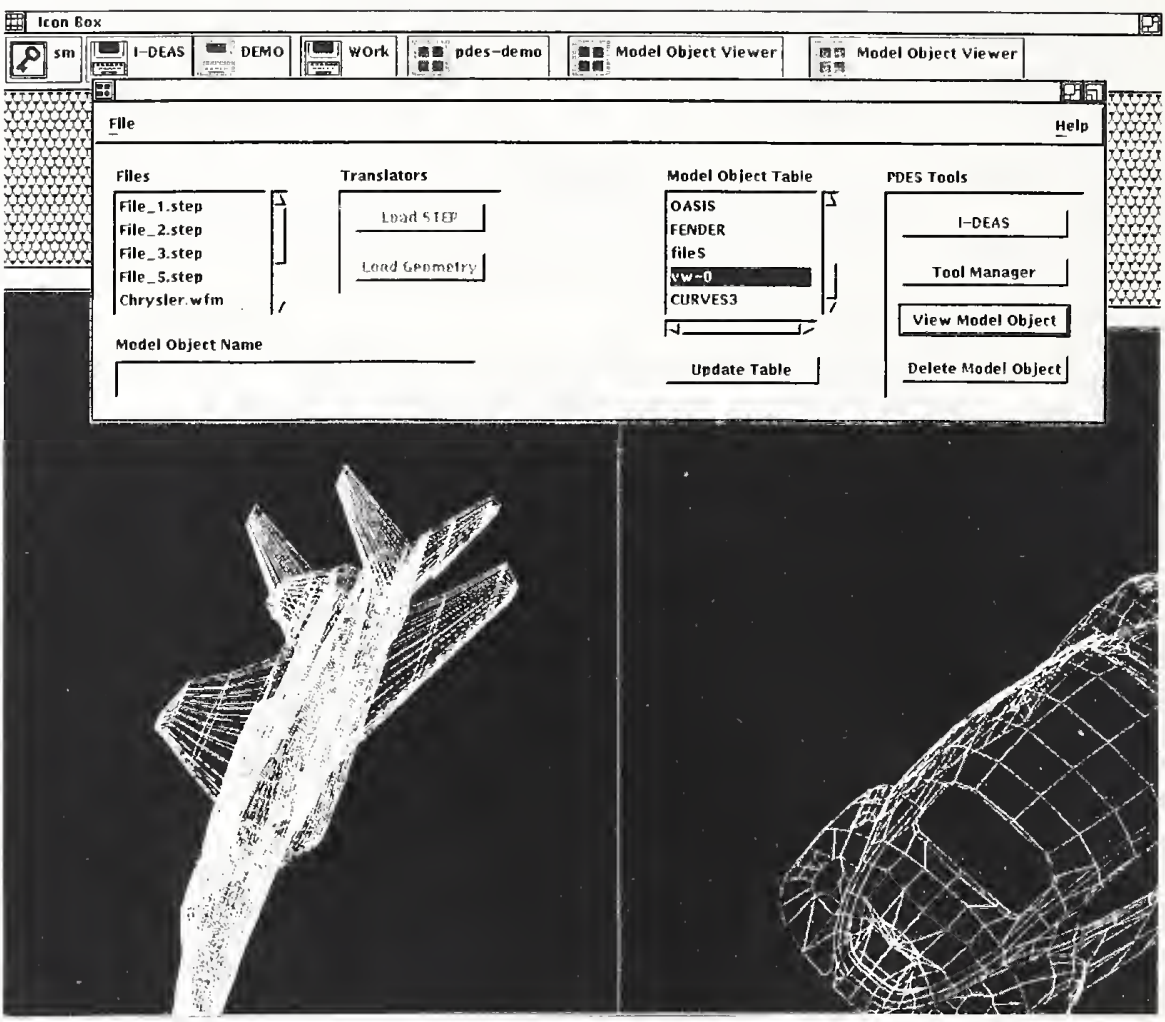

Figure 6-3. STEP-compliant wireframe images and data were transferred across applications in a demonstration of DEC's STEP Data Access Interface (SDAI). could be versioned and managed by following DEC's specification, ATIS (A Tool Integration Standard).

\subsection{PDES, Inc. Electrical/Electronics Team (NIST-Funded)}

Under funds from NIST's Electronics \& Electrical Engineering Laboratory (EEEL), Institute workers are helping to guide the development of electrical standards. From 10 through 13 December, the NIST representative to the PDES, Inc. Electrical/Electronics (PIEE) Team participated in its second meeting, held in Albuquerque. The PIEE effort focuses on modeling the activities associated with an electronic product's life cycle and creating an ISO standard that supports information exchange for the industry. The team hopes to take the federated, or harmonized model being developed by ANSI for STEP (discussed in Section 5.3.1) and integrate it into the ISO standard. The ISO standard, however, will not incorporate a feature from an ANSI standard if the feature is inconsistent with other parts of STEP. PIEE must also ensure that the STEP information model will allow only one possible representation format for a given product feature.

The NIST representative, together with a colleague from industry, is responsible for defining the tools to support the team's modeling and testing objectives, then furnishing the tools. At Albuquerque, he gained a better understanding of the priority and types of 
tools the PIEE Team will need. By meeting's end, he created and gained approval for a five-phased plan to develop two sets of tools. One set will be used by the team itself; the other will be used by industry as a reference implementation of the standard. 
National PDES Testbed-1092 Status Report

6-6 


\subsection{Testing}

TESTING METHODS define the requirements and procedures for the verification, validation, and conformance testing of elements of the emerging STEP standard and the resulting system implementations.

\subsection{Validation Testing Systems (VTS)}

Data Probe Unveiled-At NIST's annual Automation Open House (discussed in Section 8.6), the public received its first look at the improved STEP testing tool, the Data Probe.

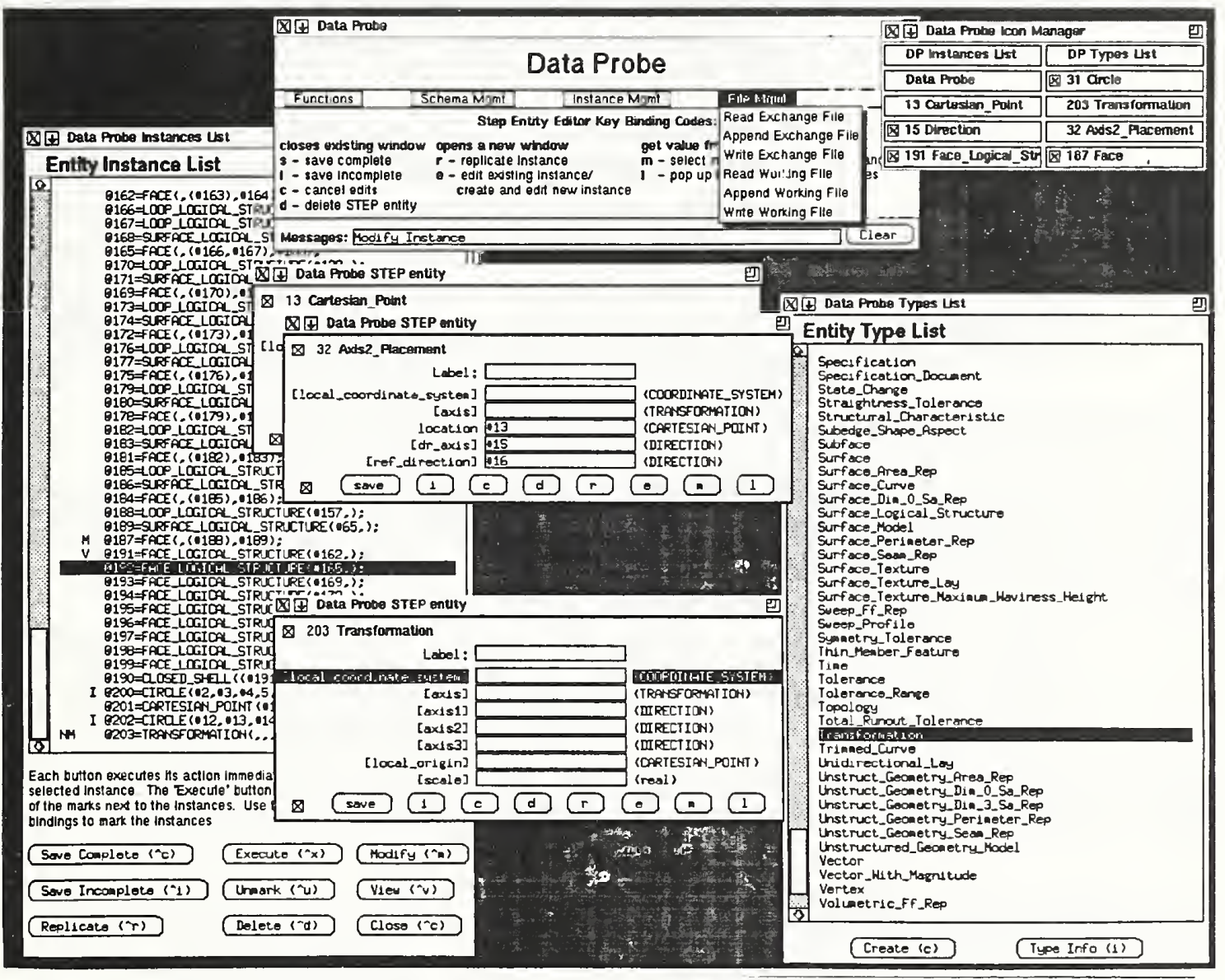

Figure 7-1. In this Data Probe screen, a user creates a STEP information unit, "Transformation" (bot $\mathrm{ctr}$ ) by picking an Entity Type (rt). She will pass it to a STEP exchange file (top ctr, menu).

Figure 7-1 shows a Data Probe screen. The key features are found in the Entity Instance List (left window); here, a user can choose an existing STEP object and perform several editing functions, either by typing-in changes or by clicking a mouse on an editing operation (bottom left window). Compared to its predecessor, Data Probe allows STEP developers to check and modify their code more naturally, and hence more quickly. When completed in 2Q92, the Data Probe will be a production-quality STEP-data editing tool, made available to the STEP community. 
Tutorials Led at Phoenix - "PDES Validation Testing" was explained at CALS Expo '91 during the track, "Standards and Testing: Competing in a Global Market." The tutorial was given by Mary Mitchell, a senior researcher at the Testbed. Mitchell proposed a methodology for validating STEP Application Protocols, explained how validation fits into the STEP development process, and described how the validation methodology is being applied to STEP.

During the PDES/STEP track, Mitchell presented an overview of STEP Toolkits. Various software tools that support testing the utility of the standard were described, including tools developed at NIST. By making these tools available, the Testbed will promote implementation by supporting the early development of prototype systems.

Reports Published-In addition to creating a working version of the Data Probe, the VTS staff issued four NIST Interagency/Internal reports (NISTIRs):

- A Proposed Testing Methodology for STEP Application Protocols (NISTIR 4684)-provides the theoretical foundation for the testing methodology used in the Testbed. The concepts presented will evolve into a concrete software architecture and design.

- Validating STEP Application Models at the National PDES Testbed (NISTIR 4735)-takes the methodologies introduced in the above report and shows how they are actually applied on a day-to-day basis in the Testbed.

- Validation Testing System Requirements (NISTIR 4636)-describes the needs of the user community in detail. The software developed in the VTS project must meet these needs.

- Architecture for the Validation Testing System Software (NISTIR 4742)-outlines the architecture for the VTS software. It describes how various software components work and explains how they relate to one another.

Major milestones for this project are illustrated in Figure 7-2.

\subsection{Conformance Testing Services}

A contract deliverable from Industrial Technology Institute, or ITI (Ann Arbor, Michigan) was completed for a January release. Requirements and Recommendations for STEP Conformance Testing (NISTIR 4743) covered ITI's FY91 contract to the CTS project. The report was edited by Sharon Kemmerer of NIST's Computer Systems Laboratory. In addition, the report was extensively reviewed by two senior Testbed participants, Mary Mitchell and Cita Furlani.

Note: Until funding stabilizes, this project will see no activity beyond any necessary overall project-management support. 


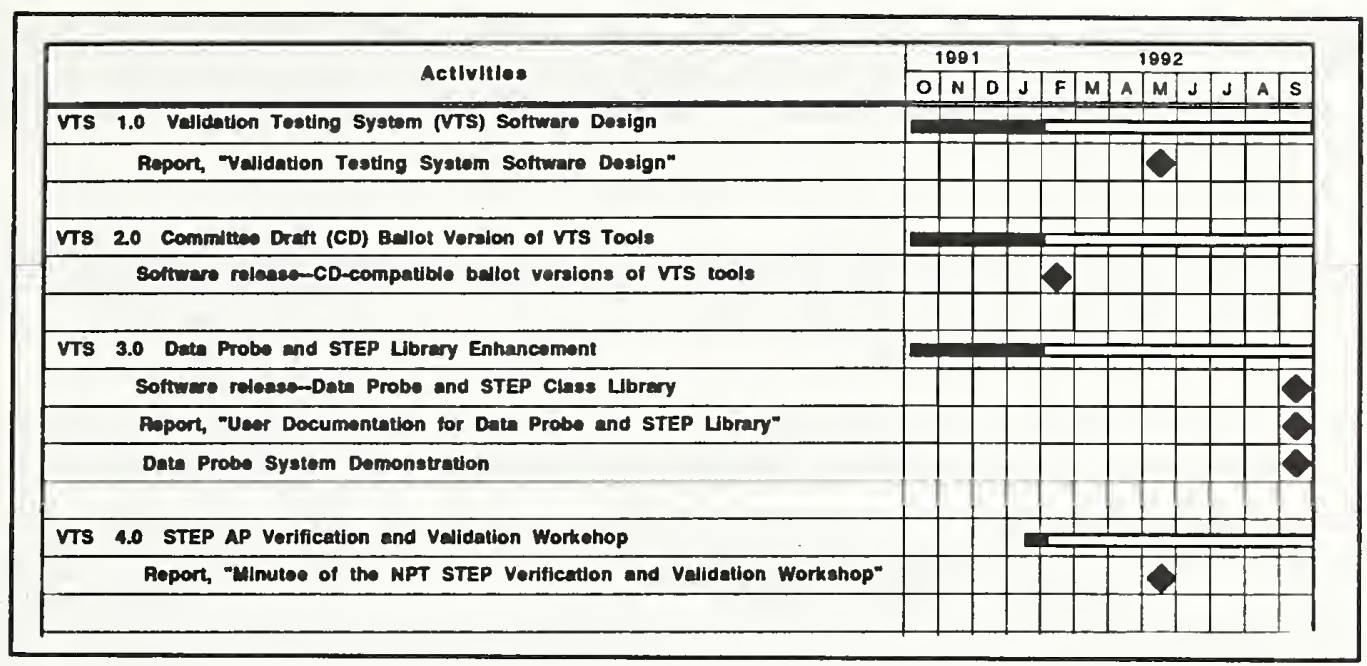

Figure 7-2. Major Milestones for Validation Testing Systems.

\subsection{STEP Implementation Tools (SIT)}

Implementation methods define how information expressed through STEP is actually managed when implemented in a real application. The STEP effort defines four levels of implementation: file exchange, working form, shared database, and knowledge base.

- Fed-X Compiler Began Being Readied for Distribution-All STEP information model specifications (such as application protocols) are described in the STEP information-modeling language, EXPRESS. As information-modeling requirements change, EXPRESS must change to support them. It follows that the Fed-X compiler-which processes the language-must track the changes to EXPRESS and support new features of the language.

In $1 \mathrm{Q} 92$, the improved version of the Fed-X compiler-Version N14-was tested by users on- and off-site. Feedback was overwhelmingly favorable. As a result, NIST began preparing to package and make it available on SOLIS. Concomitantly, the Fed-X documentation was updated and readied for printing.

- SDAI Requirements Document Drafted-PDES, Inc. held an SDAI meeting at NIST to review an initial draft specification produced by SIT manager Jim Fowler and Chia-Hui Shih, a PDES, Inc. team member from solid-modeling vendor SDRC. A number of technical issues emerged that will have to be addressed in the specification. To resolve some of these issues, Fowler paid a two-day visit to Digital Equipment Corporation (DEC)'s CAD/CAM Technology Division in Chelmsford, Massachusetts. With the issues resolved, Fowler was able to solicit contributions to the specification. An improved draft specification was expected in time for the January IPO meeting in Salt Lake City.

Toward the end of the quarter, Fowler helped to coordinate DEC's SDAI demonstration at NIST (discussed in Section 6.4). 
Major milestones for this project are illustrated in Figure 7-3.

\begin{tabular}{|c|c|c|c|c|c|c|c|c|c|}
\hline \multirow{2}{*}{ Activitles } & \multicolumn{2}{|c|}{1991} & \multicolumn{7}{|c|}{1992} \\
\hline & \begin{tabular}{|l|l|l|l|l}
$D$ & $N$ \\
$D$
\end{tabular} & $\mathrm{D}$ & $\mathbf{J}$ & \begin{tabular}{l|l}
$M$ \\
$M$
\end{tabular} & A & $M$ & $\mathrm{~J}$ & J & A $\mathrm{s}$ \\
\hline \multicolumn{10}{|l|}{ ST 1.0 Roviso EXPRESS Toolkit to STEP Version 1.0} \\
\hline \multicolumn{10}{|l|}{ Software submitted to STEP On-LIne Information Service } \\
\hline \multicolumn{10}{|l|}{ Updaled Fed-X User Documentation Set } \\
\hline \multicolumn{10}{|l|}{ SIT 2.0 Develop Draft ISO SDAI Requirements Document } \\
\hline \multicolumn{10}{|l|}{ ISO White Paper, "STEP Data Accoss Interface (SDA) Requirements Document" } \\
\hline \multicolumn{10}{|l|}{ ST 3.0 Devolop Draft SOAI Specillcation and Language Bindings } \\
\hline \multicolumn{10}{|l|}{ SDAI Functional Specfifeation and Language Bindings submitted to ISO } \\
\hline \multirow{2}{*}{\multicolumn{10}{|c|}{ SIT 4.0 STEP MIgration }} \\
\hline & & & & & & & & & \\
\hline \multicolumn{10}{|l|}{ Software submitted to STEP On-Line Information Service } \\
\hline \multicolumn{10}{|l|}{ STEP Migratlon Usor Documentation Set } \\
\hline & & & & & & & & & \\
\hline \multicolumn{10}{|l|}{ SIT 5.0 Requirements tor EXPRESS Toolkit Enhancements } \\
\hline \multicolumn{10}{|l|}{ Roport, "EXPRESS Toolkit Requirements Document" } \\
\hline & & & & & & & & & \\
\hline \multicolumn{10}{|l|}{ STT 6.0 Rovise STEP Exchenge File Parser to STEP Version 1.0} \\
\hline \multicolumn{10}{|l|}{ Soltware submitted to STEP On-Line Information Service } \\
\hline \multicolumn{10}{|l|}{ Updatod Exchange File Parser User Documentation Set } \\
\hline & & & & & I & & & & \\
\hline \multicolumn{10}{|l|}{ SIT 7.0 STEP Date Access Intorface (SDAI) Prototyping } \\
\hline Roport, "Evoluetion of STEP Data Access Intertece (SDAI) Implementetion" eubmitrod to IPO/ISO & & & & & & & & & \\
\hline & & & & & & & & & \\
\hline & & & & & & & & & \\
\hline & & & & & & & & & \\
\hline & & & & & & & & & \\
\hline
\end{tabular}

Figure 7-3. Major Milestones for STEP Implementation Tools. 


\subsection{Education and Technology Transfer} SPREADING THE WORD about the importance of STEP, and the role of PDES in
making STEP a national reality, remained an abiding priority.

\subsection{Product Data Education Goes Multimedia}

In an age in which information is increasingly "byte-sized" and visual, reports and brochures cannot always deliver the message. Yet it is important that a broad audience understand how product-data standards can enhance global competitiveness. Research has shown that the more complex a subject, the more effectively it can be clarified by visuals-particularly, visuals that engage the viewer interactively. Indeed, interactive training has saved the Pentagon millions of dollars over conventional training.

With these points in mind, the Testbed in 1Q92 completed an interactive multimedia tutorial on the history of product data. It is interactive in that the person seated before the computer screen responds to questions and decides-with the click of a "mouse"-which subject to explore next. It is multimedia in that text and graphics are commingled with animation.

Created by a NIST programmer who is also a graphic artist and instructional designer, Product Data for a Changing World highlights the ways that product data has changed from the pre-industrial age through the emerging development of STEP (Figure 8-1). As its title suggests, Product Data for a Changing World details how-and why-product data has evolved from crude sketches into a comprehensive system that defines virtually every aspect of a manufactured product, from conception through consumption. The target audience is managers, engineers, and decisionmakers working to restore American manufacturers' competitive edge.

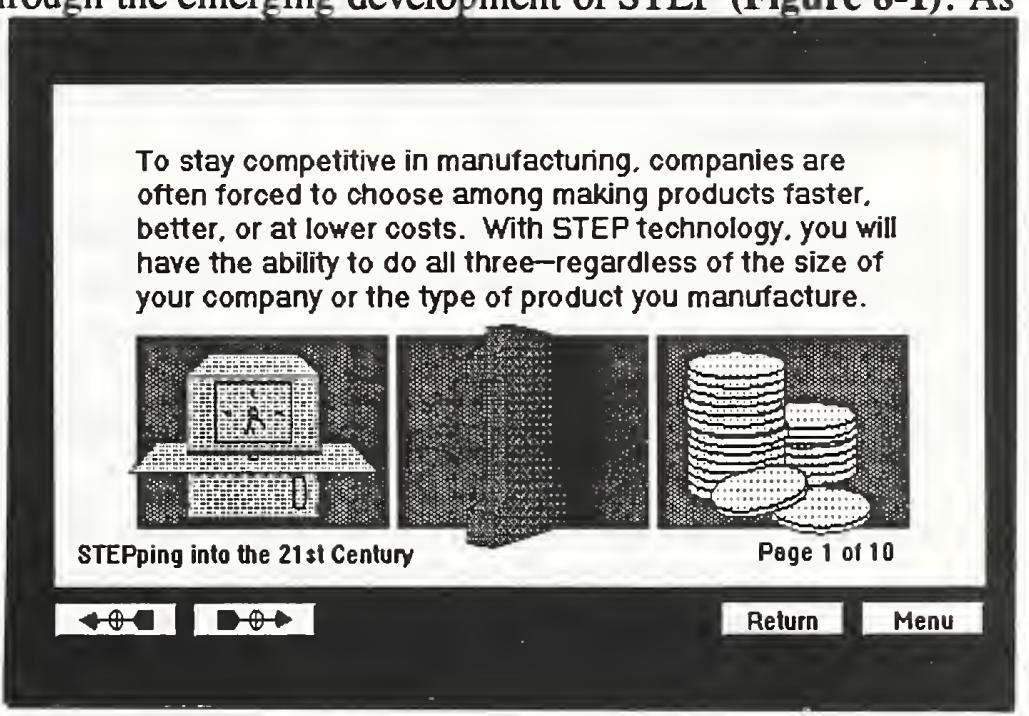

Figure 8-1. The importance of product-data standards to competitiveness is brought home in this interactive multimedia tutorial.

Product Data is the second multimedia tutorial developed by staff of the National PDES Testbed. In 1990, 
Hyperstandard invited users to explore the many facets of PDES and STEP by browsing through a menu of documents "linked" together on a single optical disc.

The new presentation was available to visitors at the Testbed booth throughout CALS Expo '91. Response was enthusiastic; many attendees asked NIST for copies. The DoC's National Technical Information Service (NTIS) has asked that Product Data become part of the agency's CALS Starter Kit packet. Others who have experienced the tutorial have suggested that it be on display in lobbies and waiting rooms of various offices and corporations involved in the CALS effort. In response to this interest, NIST has decided to make Product Data for a Changing World available to any individuals and organizations who are interested.

Compared with print and video, multimedia can be inexpensively produced and is sufficiently flexible to be easily revised or enhanced. Hence, as STEP continues to evolve, the Testbed will continue to develop interactive graphical presentations to make the standard's progress and purpose easier for nonspecialists to understand.

\subsection{Interest in PDES Sparked at CALS Expo'91}

When interviewed by Washington Technology, many of the visitors at CALS Expo '91 confessed they had never heard of PDES. That changed when Dr. Robert M. White, Undersecretary for Technology, Department of Commerce, kicked off the National Initiative for Product Data Exchange before a crowd of nearly 2,000.

White, together with ASD-PL Colin McMillan, chairs the Initiative's Executive Committee. "Many, many organizations are working on digital product data exchangerelated projects," White told the Expo attendees. "Today, America spends millions annually on more-or-less independent PDES efforts. We are wasting time and money on redundant efforts."

White's admonishing remarks spurred a strong attendance at the National PDES Testbed, the IGES/PDES Organization (IPO), and PDES, Inc. booths on the show floor.

\subsection{Testbed Personnel Conduct Expo Sessions on PDES, APs}

White was not the only speaker who helped make PDES a focus of Expo attendees:

- Howard Bloom, the acting Testbed Manager, delivered a presentation on the Testbed.

- Mark Palmer, project manager for AP Framework and Methodology, gave a presentation covering the AP methodology, the current PDES/STEP AP projects, and technical issues surrounding application protocols. 
- Cita Furlani, Product Data Engineering Group Leader at NIST, organized and chaired the track, "Standards and Testing: Competing in a Global Market."

- Chuck Stark, the PDES, Inc. liaison, together with two fellow team leaders from PDES, Inc., presented two sessions of a 3.5-hour tutorial, STEP and the PDES Activities. All told, some 90 Expo visitors took part in these tutorials. The more-than-200 copies of the presentation materials were snapped up by attendees eager to learn more.

- Mary Mitchell, a senior member of the Testbed staff, gave tutorials on STEP Toolkits and STEP Validation Methods (discussed further in Section 7.1).

\subsection{White House Assistant Visits Testbed}

On 30 October, a high-level briefing on PDES was given on-site to Colonel John Warden, Office of the Vice President. Colonel Warden is the former Deputy Director for Strategy, Doctrine, and Plans, Directorate of Plans, under the Deputy Chief of Staff for Plans and Operations, Headquarters, United States Air Force, at the Pentagon.

During the briefing, Testbed staff explained to Warden how they work closely with industry (through the PDES, Inc. consortium and IPO) and with government agencies to develop elements of STEP that meet the needs of industry and defense. While watching the Testbed in use, Warden was introduced to a PDES, Inc. member, who was being trained to use STEP software tools.

Warden, who assists Vice President Quayle on the Council on Competitiveness, was also given an overview of how product data standards improve competitiveness in global markets.

\subsection{Technical Publications Issued}

Five technical reports were completed and distributed; they are listed in Table 8-1. And, in response to telephone requests, the CALS/PDES Office mailed 13 copies of earlierpublished reports to individuals in industry and academia.

\subsection{STEP, Testbed on Display at Automation Open House}

The National PDES Testbed was one of six featured stops at NIST's annual Automation Open House, held 19-22 November. With Testbed staff serving as their hosts, some 350 visitors from government, industry, and academia learned how Testbed is helping to support STEP development. As the visitors watched, computer screens demonstrated six Testbed-developed STEP tools:

- the Fed-X compiler 


\begin{tabular}{|c|c|c|c|c|}
\hline $\begin{array}{l}\text { Month } \\
\text { Issued }\end{array}$ & $\begin{array}{l}\text { Report } \\
\text { Number }\end{array}$ & Title & Author(s) & $\begin{array}{c}\text { Discussed in } \\
\text { Section ... }\end{array}$ \\
\hline Oct. & $\begin{array}{l}\text { NISTIR } \\
4636\end{array}$ & $\begin{array}{l}\text { Validation Testing System } \\
\text { Requirements }\end{array}$ & $\begin{array}{l}\text { K. Morris, M. } \\
\text { McLay, \& P. Carr }\end{array}$ & 7.1 \\
\hline Dec. & $\begin{array}{l}\text { NISTIR } \\
4683\end{array}$ & $\begin{array}{l}\text { The Validation Testing } \\
\text { Laboratory User's Guide }\end{array}$ & $\begin{array}{l}\text { N. Breese, } \\
\text { M. McLay, } \\
\text { \& G. Silvernale }\end{array}$ & 6.2 \\
\hline Oct. & $\begin{array}{l}\text { NISTIR } \\
4684\end{array}$ & $\begin{array}{l}\text { A Proposed Testing Methodology } \\
\text { for STEP Application Protocols }\end{array}$ & M. Mitchell & 7.1 \\
\hline Dec. & $\begin{array}{l}\text { NISTIR } \\
4735\end{array}$ & $\begin{array}{l}\text { Validating STEP Application } \\
\text { Models at the National PDES } \\
\text { Testbed }\end{array}$ & $\begin{array}{l}\text { K. Morris, } \\
\text { M. Mitchell, } \\
\text { \& D. Sauder }\end{array}$ & 7.1 \\
\hline Dec. & $\begin{array}{l}\text { NISTIR } \\
4742\end{array}$ & $\begin{array}{l}\text { Architecture for the Validation } \\
\text { Testing System Software }\end{array}$ & K. Morris & 7.1 \\
\hline
\end{tabular}

- the Express-to-SQL (Structured Query Language) translator (Figure 8-2)

- a utility to output STEP physical files

- the original data editor, QDES

- the new data editor, Data Probe

- the STEP On-Line Information Service

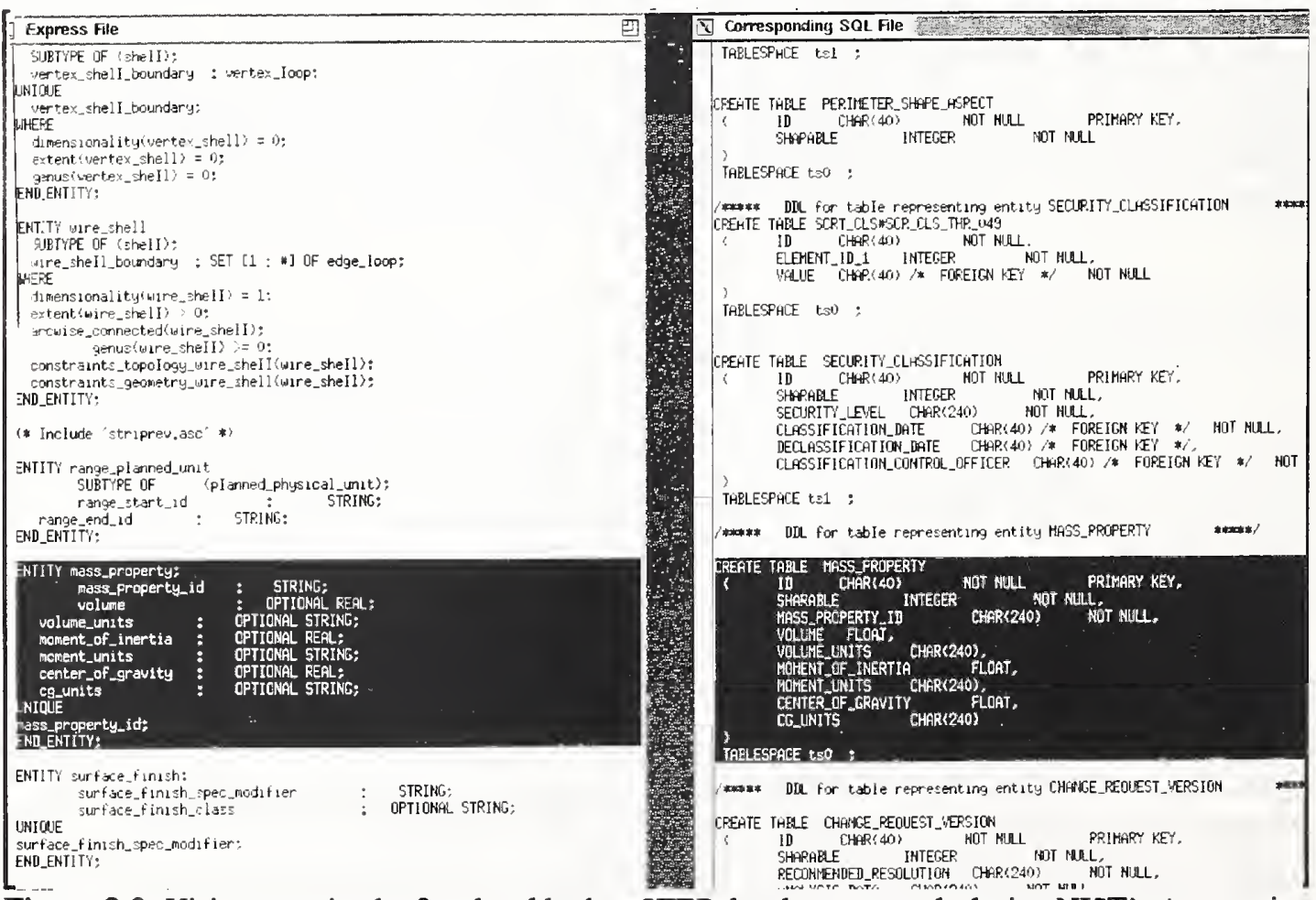

Figure 8-2. Visitors received a first-hand look at STEP development tools during NIST's Automation Open House. Shown is the Express-to-SQL translator, developed by the National PDES Testbed. 
Also demonstrated were two software tools developed by PDES, Inc.: the IGES-to-PDES translator and the $\mathrm{C} 4$ Visualizer (Figure 8-3).

Open House visitors also saw STEP-compliant wireframes, surface models, and other forms of product data displayed on DEC, IBM, and Sun workstations-brands widely used at U.S. defense plants. Elsewhere, they learned about PDES and STEP in more detail

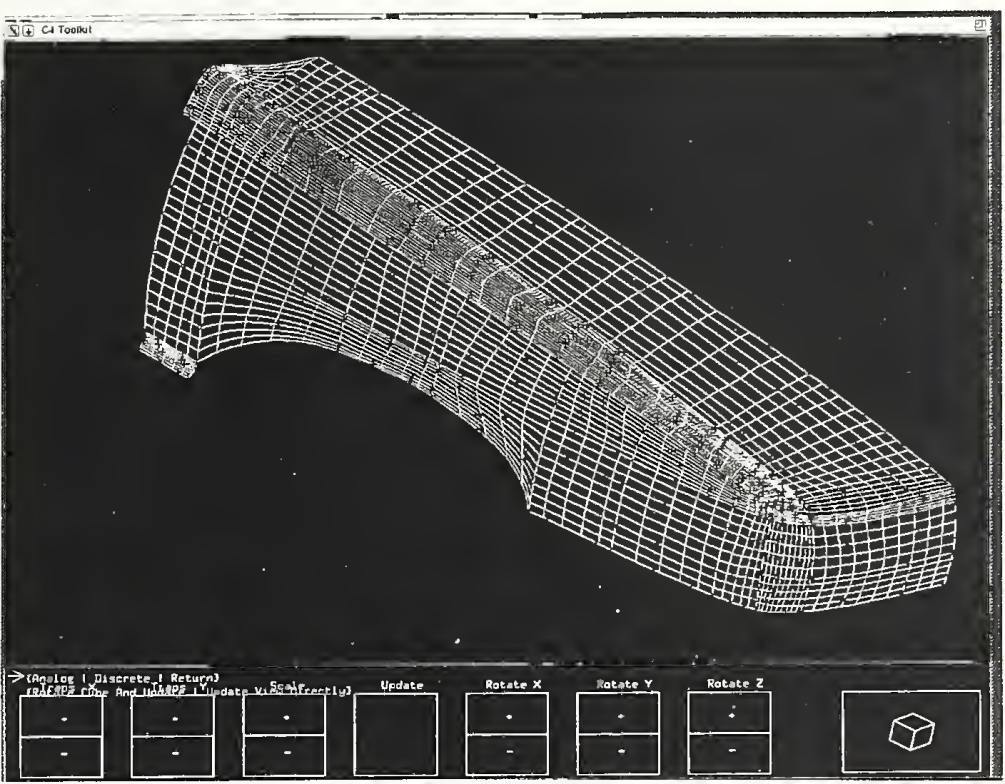

Figure 8-3. At NIST's Automation Open House, this wireframe image was rendered by the C4 Visualizer, a STEP software tool donated by PDES, Inc. member General Motors. through nine posters (Figure 8-4).

\section{Application Protocols for Mechanical Parts Production}

\section{DEFINITION:}

An Application Protocol (AP) is a specification for a subset of STEP data that can be implemented in an application system.

\section{GOAL:}

To develop a strategy for an Application Protocols key product life cycle AP's within the testbed area of expertise.

Planned Technical Activities That Will Support the APMPP Development Project

Application Protocol: Framework and Methods

Objective: - To provide a tramework lor defining, planning. and mansging AP propects.

The tramework will provide a structure to classity AP define AP scopes and boundaries. Identify integration requirements. specity required relations between APs.
and accommodate overiaps and interfaces between AP,

Application Protocol: Inspection

Obpective - To develop an AP lor inspection planning

- The inspection AP will relline the shape tolerance model and initiale activities lor an inspection-related AP.

Application Protocol: Process Planning

Objective - To identify and document intormation in commescial

process planning systems to suppor the development
of an AP for the process planning lor machining

b th mechanical parns

\section{OBJECTIVES:}

- Test and Refine Application Protocol methodology

- Provide strategy for Application Protocol development

- Examine interoperability requirements for Application Protocols

- Identify impact of 2nd implementation form (file exchange, database)

Application Protocol Development Process

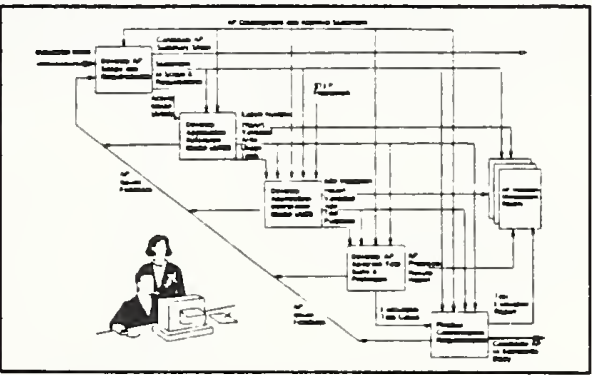

This project will result in a fully lested and validated set of application

protocola Application systems that suppon these engineenng function

- Detailed Design.

- Process Planning. and

Figure 8-4. Hundreds learned about the National PDES Testbed in posters like this one at NIST's 1991 Automation Open House. 
National PDES Testbed-1Q92 Status Report

8-6 


\begin{tabular}{|c|c|c|}
\hline \multicolumn{3}{|c|}{ 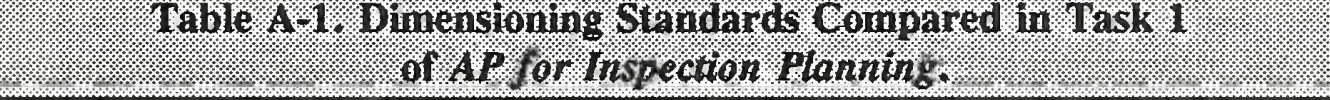 } \\
\hline Standards Body & Number & Name \\
\hline ANSI & Y14.5M-1982 & Dimensioning and Tolerancing \\
\hline ANSI/ASME & Y14.5.1 & $\begin{array}{l}\text { Mathematical Definitions of Y14.5 } \\
\text { Tolerancing Principles (draft) }\end{array}$ \\
\hline ANSI/CAM-I & DMIS 101 & $\begin{array}{l}\text { Dimensional Measuring Interface } \\
\text { Standard, Version } 2.1\end{array}$ \\
\hline ISO & $\begin{array}{l}1101 \\
1660 \\
2692 \\
5458 \\
5459 \\
\\
5460 \\
\\
8015 \\
286-1\end{array}$ & $\begin{array}{l}\text { Geometric Tolerancing } \\
\text { Dimensioning and Tolerancing Profiles } \\
\text { Maximum-Material Principle } \\
\text { Position Tolerancing } \\
\text { Datums and datum-systems for } \\
\quad \text { geometrical tolerances } \\
\text { Verification Principles and } \\
\quad \text { Methods-Guidelines } \\
\text { Fundamental Tolerancing Principle } \\
\text { System of Limits and Fits }\end{array}$ \\
\hline
\end{tabular}




\begin{tabular}{|c|c|c|}
\hline \multicolumn{3}{|c|}{$\begin{array}{l}\text { Table A-2. Testbed Staff Members' ISO Roles that are? } \\
\text { Candidates for Funding Irom the IFOISO Support Project. }\end{array}$} \\
\hline Role & ISO Entity & Entity Name \\
\hline \multicolumn{3}{|c|}{ STEP Parts } \\
\hline Owner & Part 45 & $\begin{array}{l}\text { Integrated Generic Resources: } \\
\text { Materials }\end{array}$ \\
\hline Owner & Part 47 & $\begin{array}{l}\text { Integrated Generic Resources: } \\
\text { Shape Tolerances }\end{array}$ \\
\hline \multicolumn{3}{|c|}{ 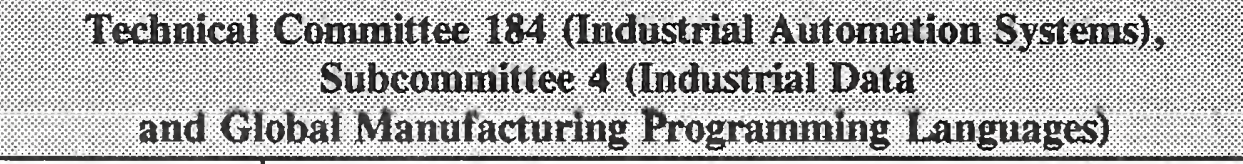 } \\
\hline $\begin{array}{l}\text { NIST Rep- } \\
\text { resentative }\end{array}$ & \multicolumn{2}{|c|}{ U.S. Technical Advisory Group } \\
\hline $\begin{array}{l}\text { Technical } \\
\text { Contributor }\end{array}$ & Working Group 4 & Qualification and Integration \\
\hline Leader & $\begin{array}{l}\text { Working Group 4, } \\
\text { Project } 2\end{array}$ & Qualification and Validation \\
\hline Co-leader & $\begin{array}{l}\text { Working Group 4, } \\
\text { Project } 4\end{array}$ & $\begin{array}{l}\text { Integration Technology and } \\
\text { Training }\end{array}$ \\
\hline Convener & \multirow[b]{2}{*}{ Working Group 5} & \multirow[b]{2}{*}{ STEP Development Methods } \\
\hline $\begin{array}{l}\text { Technical } \\
\text { Contributor }\end{array}$ & & \\
\hline $\begin{array}{l}\text { Technical } \\
\text { Contributor }\end{array}$ & Working Group 6 & Conformance Testing \\
\hline $\begin{array}{l}\text { Technical } \\
\text { Contributor }\end{array}$ & Working Group 4 & Implementation Specifications \\
\hline $\begin{array}{l}\text { Technical } \\
\text { Contributor }\end{array}$ & Working Group 8 & $\begin{array}{l}\text { Industrial Manufacturing } \\
\text { Management Data }\end{array}$ \\
\hline
\end{tabular}


Table A-3. Testbed Starf

Nembers' TPO Roles that are

Candidates for Funding frem the POISO Support Project.

\begin{tabular}{||l|l|}
\hline \multicolumn{1}{|c|}{ Committee } & \multicolumn{1}{c|}{ Role } \\
\hline Materials Committee & chair \\
\hline $\begin{array}{l}\text { PDES Development } \\
\text { Methods }\end{array}$ & co-chair \\
\hline $\begin{array}{l}\text { Shape } \\
\text { Tolerance } \\
\text { Committee }\end{array}$ & chair \\
\cline { 2 - 2 } & $\begin{array}{l}\text { technical } \\
\text { contributor }\end{array}$ \\
\hline $\begin{array}{l}\text { STEP Implementation } \\
\text { Specifications } \\
\text { Committee }\end{array}$ & chair \\
\cline { 2 - 3 } & $\begin{array}{l}\text { technical } \\
\text { contributors }\end{array}$ \\
\hline
\end{tabular}




\begin{tabular}{|c|c|c|}
\hline \multicolumn{3}{|c|}{ 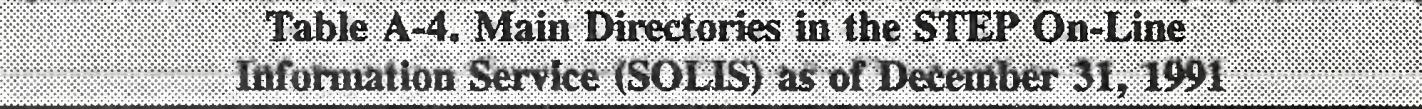 } \\
\hline Name & Installed & Description \\
\hline docs & $07-29-91$ & Readme file and other documentation \\
\hline latex & 10-11-91 & LAT $_{E} \mathrm{X}$ style files used in some of the STEP parts \\
\hline listings & $10-11-91$ & listings of directories' contents (downloadable version of BBS screens) \\
\hline nptdocs & $10-08-91$ & National PDES Testbed (NPT) documents \\
\hline npttools & $08-26-91$ & National PDES Testbed (NPT) tools \\
\hline old 1 & $03-28-91$ & previous version of STEP Part 1 \\
\hline old 21 & $01-28-91$ & previous version of STEP Part 21 \\
\hline old41 & $06-07-91$ & previous version of STEP Part 41 \\
\hline old42 & $03-13-91$ & previous version of STEP Part 42 \\
\hline old44 & $11-05-90$ & previous version of STEP Part 44 \\
\hline old45 & $12-03-90$ & previous version of STEP Part 45 \\
\hline old47 & $03-28-91$ & previous version of STEP Part 47 \\
\hline old101 & $06-26-91$ & previous version of STEP Part 101 \\
\hline old203 & $04-05-91$ & previous version of STEP Part 203 \\
\hline old 204 & $11-29-90$ & previous version of STEP Part 2i . \\
\hline part1 & $10-07-91$ & STEP Part 1, Version 8, First Edition \\
\hline part11 & $04-29-91$ & STEP Part 11 \\
\hline part21 & $03-12-91$ & STEP Part 21 \\
\hline part31 & $10-08-91$ & STEP Part 31 \\
\hline part41 & $09-06-91$ & STEP Part 41, Version 6 \\
\hline part42 & $03-X X-91$ & STEP Part 42, First Edition \\
\hline part43 & $07-26-91$ & STEP Part 43, N28 (P2) \\
\hline part44 & $08-16-91$ & STEP Part 44, Version 1 \\
\hline part49 & $12-03-90$ & STEP Part 45 \\
\hline part46 & $07-25-91$ & STEP Part 46, First Edition \\
\hline part48 & $04-X X-91$ & STEP Part 42, First Edition \\
\hline part49 & $10-17-90$ & STEP Part 49, First Release \\
\hline part101 & $07-11-91$ & STEP Part 101, Version 2.7 \\
\hline part102 & $12-19-90$ & STEP Part 102, Version 4.0 \\
\hline part104 & $01-03-91$ & STEP Part 104, Version 1.0 \\
\hline part202 & $07-18-91$ & STEP Part 202, Working Group 3, N62 \\
\hline part203 & $08-21-91$ & STEP Part 203, Version 7 \\
\hline part204 & $10-11-91$ & STEP Part 204, Version 2.0 \\
\hline part205 & $11-11-90$ & STEP Part 205, Version 1.1 \\
\hline phase 1 & $08-26-91$ & PDES, Inc. Phase-I Deliverables \\
\hline wg7docs & $11-01-91$ & documents from Working Group 7 \\
\hline
\end{tabular}




\begin{tabular}{|c|c|c|}
\hline \multirow[t]{4}{*}{$\begin{array}{l}\text { NIST-114A } \\
\text { (REV. 3-80) }\end{array}$} & \multirow{3}{*}{$\begin{array}{l}\text { U.S. DEPARTMENT OF COMMERCE } \\
\text { NATIONAL INSTITUTE OF STANDARDS AND TECHNOLOGY } \\
\text { BIBLIOGRAPHIC DATA SHEET }\end{array}$} & $\begin{array}{l}\text { 1. PUBLCATION OR REPOAT NUMBER } \\
\text { NISTIR } 4787\end{array}$ \\
\hline & & 2 PEAFOAMING ORQANIZATION AEPORT NUMBER \\
\hline & & N/A \\
\hline & & March 1992 \\
\hline
\end{tabular}

4. TITLEAND SUBTTILE

Status Report for First Quarter, FY92

(1 October Through 31 December 1991)

5. AUTHOA(S)

Howard M. Bloom

6. PERFOAMINQ ORQAMIZATION (IF JOINT OR OTHER THAN MIST, SEE INSTAUCTIONS)

U.S. DEPARTMENT OF COMMERCE

MATIONAL INSTITUTE OF STANDARDS AND TECHNOLOQY

CATHERSBURO, MD 20890

\begin{tabular}{|l|}
\hline 7. CONTRACT/ORANT NUMBER \\
\hline o. TYPE OF REPORT AND PERIOD COVERED \\
Status Report $(10 / 01-12 / 31 / 91)$
\end{tabular}

9. SPOMSORINO ORQANIZATION MAME AND COMPLETE ADDRESS (STREET, CITY, STATE, ZIP)

U.S. Department of Defense

CALS Evaluation and Integration Office

The Pentagon

Washington, DC 20301-8000

10. SUPPLEMENTAAY NOTES

11. ABSTRACT (A 200-WORD ORLESS FACTUAL SUMMAAY OF MOST SIGNIFICANT INFOAMATION. IF DOCUMENT INCLUDES A SIGMIFICANT BIBUOGRAPHY OR UTERATURE SURVEY, MENTION IT HERE)

In IQ92, much of the activity of the National PDES Testbed revolved around two major events: CALS Expo ' 91 and the joint meeting of IPO (IGES/PDES Organization) and ISO (International Organization for Standardization). Together, these events accounted for more than half of nearly 30 Testbed-funded trips.

At these events, Testbed staff enhanced their coordination with the STEP (STandard for the Exchange of Product model data) community and took several leads in charting the course of STEP's development. Testbed staff were elected to chair three STEP-related working groups or committees. And under the Testbed project "AP for Inspection Plaming," a work-sharing agreement was informally established with counterparts from Europe's ESPRIT program.

Nine technical thrusts of the PDES, Inc. consortium were supported, including electrical/ electronics standards. The Testbed Hotline fielded 20 calls, while the STEP On-Line

Information Service was used to transmit more than 900 files to users.

A prototype STEP Data Access Interface (SDAI) implementation was demonstrated, while a major upgrade of the Fed-X compiler was readied for shipping.

Five technical reports were issued. Through tutorials and technical sessions, Testbed staff played prominent educational roles at CALS Expo ' 91.

12 KEY WOADS (6 TO 12 ENTRIES; ALPHABETICAL ORDER; CAPITALIE ONLY PROPER MAMES; AMD SEPARATE KEY WORDS BY SEMICOLONS) AP; application protocols; CALS; configuration management; National PDES Testbed; PDES; product data; SDAI; STEP; STEP Data Access Interface; test; validation

FON OFFICLAL DISTRIBUTION. DO MOT REEEASE TO MATIOMAL TECHMICAL HFOAMATION SERVCE (NTIS).

ORDER FROM SUPERINTENDENT OF DOCUMENTS, U.S. GOVERMMENT PRINTINO OFFICE, WASHINOTON, DC 20402

ORDER FROM MATIOMLL TECHNICAL INFOAMATION SERVCE (NTIS), SPRINOFED, VA 22161.

14. NUMBER OF PAINTED PACES

60

15. PRICE

A04 


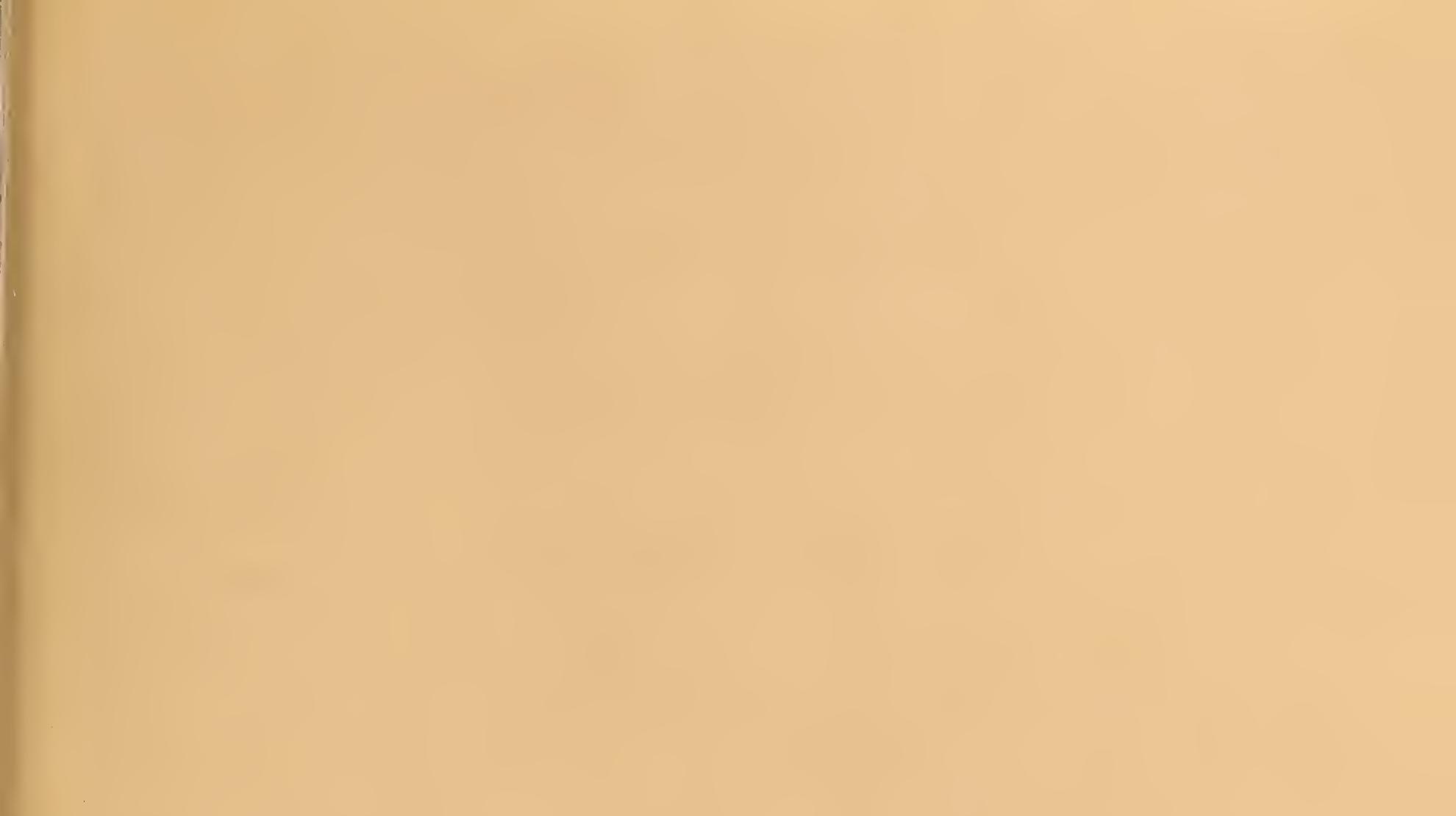


\begin{tabular}{|c|c|c|c|}
\hline \multicolumn{4}{|c|}{ 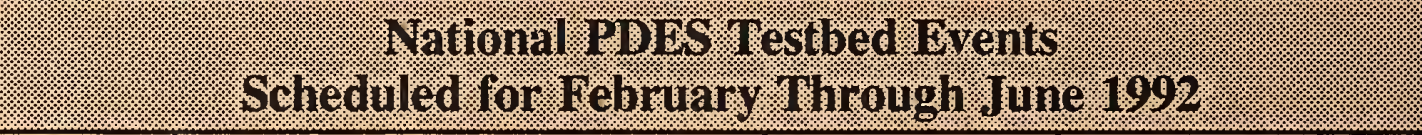 } \\
\hline Date(s) & Event & Location & Contact \\
\hline $\begin{array}{l}18-21 \\
\text { Feb. }\end{array}$ & $\begin{array}{l}\text { PDES, Inc. Electrical Team } \\
\text { Meeting }\end{array}$ & $\begin{array}{l}\text { Gaithersburg, } \\
\text { Maryland }\end{array}$ & $\begin{array}{l}\text { Mr. Chuck Stark } \\
\text { (301) } 975-3416\end{array}$ \\
\hline $\begin{array}{l}18-21 \\
\text { Feb. }\end{array}$ & $\begin{array}{l}\text { Meeting of PDES, Inc. CDIM } \\
\text { B4 (Manufacturing Data Team) }\end{array}$ & $\begin{array}{l}\text { Gaithersburg, } \\
\text { Maryland }\end{array}$ & $\begin{array}{l}\text { Mr. Jesse Crusey } \\
\text { (301) 975-3566 }\end{array}$ \\
\hline $\begin{array}{l}13-14 \\
\text { April }\end{array}$ & AP Validation Workshop & $\begin{array}{l}\text { Seattle } \\
\text { (ISO/IPO } \\
\text { Meeting) }\end{array}$ & $\begin{array}{l}\text { Mr. Sandy Ressler } \\
\text { (301) 975-3549 }\end{array}$ \\
\hline $\begin{array}{l}8-12 \\
\text { June }\end{array}$ & $\begin{array}{l}\text { Meeting of PDES, Inc. CDIM } \\
\text { B4 (Manufacturing Data Team) }\end{array}$ & $\begin{array}{l}\text { Gaithersburg, } \\
\text { Maryland }\end{array}$ & $\begin{array}{l}\text { Mr. Jesse Crusey } \\
\text { (301) } 975-3566\end{array}$ \\
\hline
\end{tabular}

